\title{
Influence of Bearing Stiffness on the Nonlinear Dynamics of a Shaft-Final Drive System
}

\author{
Xu Jinli, Wan Lei, and Luo Wenxin \\ School of Mechanical and Electronic Engineering, Wuhan University of Technology, Hubei 430070, China \\ Correspondence should be addressed to Wan Lei; wanlei1000815@126.com
}

Received 18 February 2016; Revised 3 May 2016; Accepted 26 May 2016

Academic Editor: Tai Thai

Copyright (C) $2016 \mathrm{Xu}$ Jinli et al. This is an open access article distributed under the Creative Commons Attribution License, which permits unrestricted use, distribution, and reproduction in any medium, provided the original work is properly cited.

\begin{abstract}
The bearing stiffness has a considerable influence on the nonlinear coupling vibration characteristics of the shaft-final drive system. A 14-DOF nonlinear coupled vibration model was established by employing the lumped mass method so as to identify the coupling effects of the bearing stiffness to the vibration response of the shaft-final drive system. The engine's torque ripple, the alternating load from the universal joint (U-joint), and the time-varying mesh parameters of hypoid gear of the shaft-final drive system were also considered for accurate quantitative analysis. The numerical analysis of the vibration response of the coupled system was performed and the experimental measurements were carried out for the validation test. Results show that, at the given driving speed, improving the bearing stiffness can reduce the vibration response of the given coupled system; however, when the bearing stiffness increases to a critical value, the effects of bearing stiffness on the vibration reduction become insignificant; when the driving speed changes, the resonance regions of the coupled system vary with the bearing stiffness. The results are helpful to determine the proper bearing stiffness and the optimum control strategy for the shaft-final drive system. It is hoped that the optimal shaft-final drive system can provide good vibration characteristics to achieve the energy saving and noise reduction for the vehicle application.
\end{abstract}

\section{Introduction}

It is a common case in vehicles that power is transmitted through shafts and gears which are not in a direct line; this layout is even more complex with all-wheel drive vehicles. Some precision components are inherently nonlinear; for example, the hypoid gear pair inside the gearbox is often coupled with bearing systems. On account of the increasing demand for high NVH performance, the research in the field of parameter matching on the transmission system becomes very important. As one of the major parameters in a shaftfinal drive system, the bearing stiffness significantly affects the performance of a high-speed pinion shaft and leads to the coupled vibration of the rear axle assembly $[1,2]$.

In the transmission system, the dynamic mesh force excited by the transmission error is believed to be an important vibration source. Therefore, some considerable research on the gear system has been carried on in recent years. Lim and Singh [3] proposed and established the basic theory and coupling mechanism of vibration transmission through rolling element bearing. Donley et al. [4] studied the three-dimensional stress of a gear pair with finite element method. Bibel et al. [5] considered the contact stress analysis of spiral bevel gears with the invariable mesh point and lineof-action. Gosselin et al. [6] derived a general formula and applied it to the load distribution and transmission error of spiral bevel gear. Theodossiades et al. $[7,8]$ gave a model method to analyze the dynamic characteristic using timevarying stiffness and backlash nonlinearity. Wang et al. $[9,10]$ carried out the analysis and comparison from the gear pair to the gear system with the bearing. Cheng and Lim [11, 12] developed an analytical framework for analyzing both linear and nonlinear pure vibration characteristics of geared rotor system. Tao [13] further developed the coupled multibody dynamics and vibration model with the practical cases in his work. Yang and Lim [14] proposed a new capability to analyze the dynamic interaction of gear mesh characteristics and time-varying bearing stiffness.

The tapered roller bearing (TRB) is widely used to compensate the installation errors along the axial and radial directions and the displacement by the movement of transmission system; the bearing stiffness in rotor-bearing system 


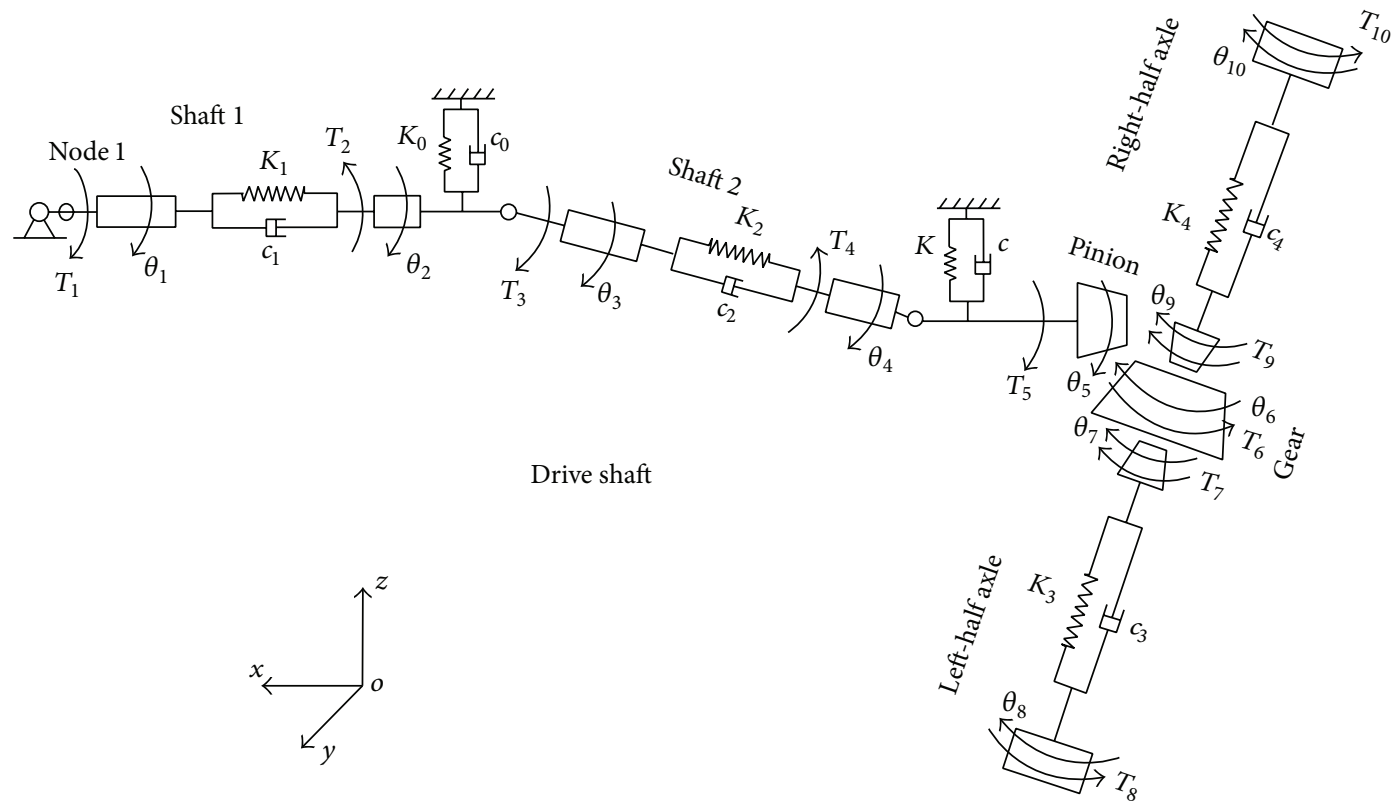

FIgURE 1: Mathematical model of a shaft-final drive system.

can significantly affect the dynamic characteristics including natural frequencies and dynamic response [15]. In recent years, a theoretical analysis of lateral response and the optimization algorithm via the enhanced genetic algorithm was presented in [16]. The running error conditions of the misalignment rotor systems connected by the gear coupling were indicated in [17]. In [18], a nonlinear dynamic model of a spur gear pair with linear models of shafts, bearings, and disks was developed. Considering the rotor dynamic balance, the flexible rotor bearing system was studied by numerical analysis elsewhere [19-21]. These researches mentioned above mainly focused on the internal incentives of gear or rotor system; the interactional relationships between transmission system and the influence of bearing stiffness on a shaft-final drive system were still not well defined [22]; few studies have been done on fluctuations of the system with transmission error in which the bearing stiffness changes with the speed in operation.

In this investigation, both nonuniformity of multiple Ujoints and time-varying mesh parameters of hypoid gear are considered, a 14-DOF nonlinear model is established, and the numerical optimisation method is proposed to analyze the influence of bearing stiffness on the nonlinear dynamics of the shaft-final drive. Then the transmission system of a rear wheel drive vehicle is taken as an example to obtain the reasonable region of bearing stiffness; experiments are carried out to demonstrate the effectiveness of this method by simultaneously optimising system stiffness.

\section{Mathematical Model}

2.1. Nonlinear Dynamic Model. The shaft-final drive system model is shown in Figure 1. It mainly consists of the drive shaft, gears, and rear axle parts.
For an effective dynamic model, the lumped mass method is adopted to deal with the components and parts. It allocates the moment of inertia of the shaft to the $\mathrm{U}$-joints and pinion, the driven gear and differential can be counted as an assembly with a concentrated mass, the flexible shaft can be described by torsion springs and dampers, and the paired mounting bearings of the reducer can be treated as a whole and simulated by a spring-damper system. To simplify the calculation, the friction and lubrication and some inertia of the small components such as the needle bearings in the Ujoints are neglected [23].

2.2. Universal Joint Geometry. On the basis of U-joints kinematics, there is

$$
\tan \theta_{2}=\tan \theta_{3} \cdot \cos \alpha_{1},
$$

where $\theta_{2}$ and $\theta_{3}$ are the input and output angle of $\mathrm{U}$-joint, respectively, $\alpha_{1}$ is the axial angle, and the angular speed and angular acceleration of main drive shaft are defined; thus,

$$
\begin{gathered}
\dot{\theta}_{3}=\frac{\cos \alpha_{1}}{\left(1+\cos \alpha_{1}^{2}\right) / 2-\cos 2 \theta_{2} \cdot\left(1-\cos \alpha_{1}^{2}\right) / 2} \dot{\theta}_{2}, \\
\ddot{\theta}_{3}=\frac{\ddot{\theta}_{2}}{A-B \cos 2 \theta_{2}}-\frac{2 B \sin 2 \theta_{2}}{\left(A-B \cos 2 \theta_{2}\right)}\left(\dot{\theta}_{2}\right)^{2}, \\
A=\frac{1+\cos ^{2} \alpha_{1}}{2 \cos \alpha_{1}}, B=\frac{1-\cos ^{2} \alpha_{1}}{2 \cos \alpha_{1}} .
\end{gathered}
$$

Similarly, $\theta_{4}$ and $\theta_{5}$ also share the aforementioned relationship.

2.3. Mesh Force Analysis. In order to make quantitative analysis, the uniform load of the pinion is replaced by the 

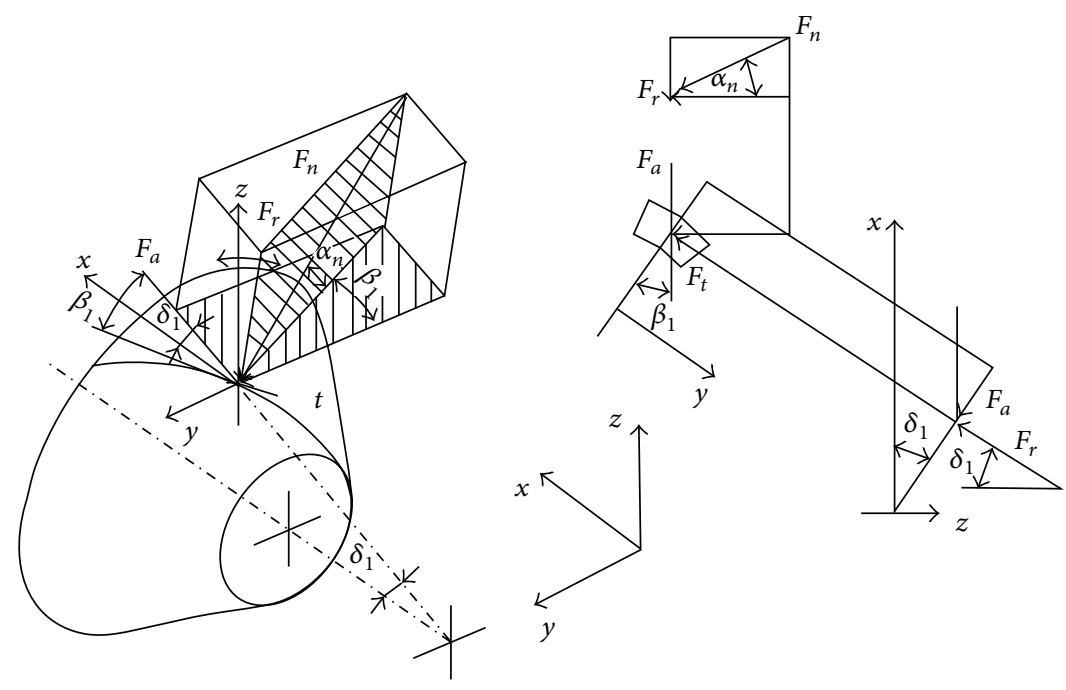

FIGURE 2: Force analysis of the pinion.

concentrated force acting on midpoint of the face width; the simplified mechanical model is shown in Figure 2.

In process of the pinion mesh transmission, the normal force at the contact point and its components along $x$-, $y$-, and $z$-axes are of the following form:

$$
\begin{aligned}
& F_{n}=k_{m}(t) f\left(x_{n}\right)+c_{m} \dot{x}_{n}, \\
& F_{x}=-F_{n} \cos \alpha_{n} \sin \beta_{1} \cos \delta_{1}+F_{n} \sin \alpha_{n} \sin \delta_{1}, \\
& F_{y}=-F_{n} \cos \alpha_{n} \sin \beta_{1} \cos \delta_{1}-F_{n} \sin \alpha_{n} \cos \delta_{1}, \\
& F_{z}=-F_{n} \cos \alpha_{n} \cos \beta_{1} .
\end{aligned}
$$

The gear pair mesh stiffness function $k_{m}(t)$ is

$$
k_{m}(t)=k_{m}+\sum_{i=1}^{N} k_{A i} \cos \left(i \Omega_{h} t+\varphi_{k}\right) .
$$

The gear backlash function $f$ can be expressed by the nonlinear combination:

$$
f\left(x_{n}\right)= \begin{cases}x_{n}-b, & x_{n} \geq b, \\ 0, & -b \leq x_{n} \leq b, \\ x_{n}+b, & x_{n} \leq-b .\end{cases}
$$

The relative displacement of the normal direction at the contact point $x_{n}$ is

$$
\begin{aligned}
x_{n}= & a_{1}\left(x_{p}-x_{g}\right)+a_{2}\left(y_{p}-y_{g}\right) \\
& +a_{3}\left(z_{p}-z_{g}+R_{p} \theta_{p}-R_{g} \theta_{g}\right)-e(t) .
\end{aligned}
$$

The synthetic error $e(t)$, in consideration of manufacturing factors, can be described as

$$
e(t)=e_{0}+\sum_{i=1}^{N} e_{A i} \cos \left(i \Omega_{n} t+\varphi_{e}\right) .
$$

Generally, with $e_{0}=0$, the coefficients in (6) can be expressed as follows:

$$
\begin{aligned}
& a_{1}=\cos \alpha_{n} \sin \beta_{1} \cos \delta_{1}-\sin \alpha_{n} \sin \delta_{1}, \\
& a_{2}=\cos \alpha_{n} \sin \beta_{1} \sin \delta_{1}+\sin \alpha_{n} \cos \delta_{1}, \\
& a_{3}=\cos \alpha_{n} \cos \beta_{1} .
\end{aligned}
$$

\section{Governing Differential Equations}

3.1. Dynamic Differential Equations. Based on the kinetics of the shaft and the mesh force analysis of the hypoid gear, the differential equations of the shaft-final drive system are as follows:

$$
\begin{array}{r}
J_{1} \ddot{\theta}_{1}+c_{1}^{\prime}\left(\dot{\theta}_{1}-\dot{\theta}_{2}\right)+K_{1}^{\prime}\left(\theta_{1}-\theta_{2}\right)=T_{1}, \\
J_{2} \ddot{\theta}_{2}+c_{2}\left(\dot{\theta}_{2}-\dot{\theta}_{1}\right)+K_{2}\left(\theta_{2}-\theta_{1}\right)=-T_{2}, \\
J_{3} \ddot{\theta}_{3}+c_{3}\left(\dot{\theta}_{3}-\dot{\theta}_{4}\right)+K_{3}\left(\theta_{3}-\theta_{4}\right)=T_{3}, \\
J_{4} \ddot{\theta}_{4}+c_{4}\left(\dot{\theta}_{4}-\dot{\theta}_{3}\right)+K_{4}\left(\theta_{4}-\theta_{3}\right)=-T_{4}, \\
J_{5} \ddot{\theta}_{5}-F_{z} R_{5}=T_{5}, \\
J_{6} \ddot{\theta}_{6}+F_{z} R_{6}=-T_{6}, \\
J_{7} \ddot{\theta}_{7}+c_{7}\left(\dot{\theta}_{7}-\dot{\theta}_{8}\right)+K_{7}\left(\theta_{7}-\theta_{8}\right)=T_{7}, \\
J_{8} \ddot{\theta}_{8}+c_{8}\left(\dot{\theta}_{8}-\dot{\theta}_{7}\right)+K_{8}\left(\theta_{8}-\theta_{7}\right)=-T_{8}, \\
m_{x p} \ddot{\bar{x}}_{p}+c_{p x} \dot{\bar{x}}_{p}+K_{p x} \bar{x}_{p}=F_{x}, \\
m_{y p} \ddot{\bar{y}}_{p}+c_{p y} \dot{\bar{y}}_{p}+K_{p y} \bar{y}_{p}=F_{y}, \\
m_{z p} \ddot{\bar{z}}_{p}+c_{p z} \dot{\bar{z}}_{p}+K_{p z} \bar{z}_{p}=F_{z}, \\
m_{x g} \ddot{\bar{x}}_{g}+c_{g x} \dot{\bar{x}}_{g}+K_{g x} \bar{x}_{g}=-F_{x},
\end{array}
$$




$$
\begin{aligned}
& m_{y g} \ddot{\bar{y}}_{g}+c_{g y} \dot{\bar{y}}_{g}+K_{g y} \bar{y}_{g}=-F_{y}, \\
& m_{z g} \ddot{\bar{z}}_{g}+c_{g z} \dot{\bar{z}}_{g}+K_{g z} \bar{z}_{g}=-F_{z} .
\end{aligned}
$$

To simplify the model, the intermediate support bearing assembly can be treated as a $K_{0}-c_{0}$ elastic system; the $K_{1}^{\prime}$ and $c_{1}^{\prime}$ are the equivalent values of the two components of intermediate support bearing assembly and intermediate shaft.

3.2. Nondimensionalization Parameters. The difference of parameter magnitude is obvious; for instance, the magnitude of stiffness is generally $10^{7}$ to $10^{9}$, but the vibration response is about $10^{-6}$, and some parameters in (9) are variable and nonlinear, so it is necessary for better solving to convert the dimension equations to nondimensionalization. The displacement is normalized by half of the gear backlash $b$ and the frequency is normalized by the natural frequency of the gear pair $\omega_{n}$; the conversion parameters are of the following form:

$$
\begin{aligned}
& m_{i}=\frac{J_{i}}{R_{i}^{2}}, \\
& k_{i}=\frac{K_{i}}{\left(m_{i} \omega_{n}^{2} R_{i}^{2}\right)}, \\
& \varsigma_{i}=\frac{c_{i}}{\left(2 m_{i} \omega_{n} R_{i}^{2}\right)}, \\
& x_{i}=\frac{R_{i} \theta_{i}}{b}, \\
& \dot{x}_{i}=\frac{R_{i} \dot{\theta}_{i}}{\left(b \omega_{n}\right)}, \\
& \ddot{x}_{i}=\frac{R_{i} \dot{\theta}_{i}}{\left(b \omega_{n}^{2}\right)}, \\
& x_{n}=\frac{\bar{x}_{n}}{b}, \\
& \dot{x}_{n}=\frac{\dot{\bar{x}}_{g}}{\left(b \omega_{n}\right)} \text {, } \\
& \ddot{x}_{n}=\frac{\ddot{\bar{x}}_{g}}{\left(b \omega_{n}^{2}\right)} \text {, } \\
& x_{p(g)}=\frac{\bar{x}_{p(g)}}{b} \text {, } \\
& \dot{x}_{p(g)}=\frac{\dot{\bar{x}}_{p(g)}}{\left(b \omega_{n}\right)}, \\
& \ddot{x}_{p(g)}=\frac{\ddot{\bar{x}}_{p(g)}}{\left(b \omega_{n}^{2}\right)},
\end{aligned}
$$

$$
k_{p(g) j}=\frac{K_{p(g) j}}{\left(m_{p(g) j} \omega_{n}^{2}\right)},
$$$$
\varsigma_{p(g) j}=\frac{c_{p(g) j}}{\left(2 m_{p(g) j} \omega_{n}\right)},
$$$$
k_{m p j}(t)=\frac{K_{m}(\bar{t})}{\left(m_{j p} \omega_{n}^{2}\right)},
$$$$
\varsigma_{m p j}=\frac{c_{m}}{\left(2 m_{j p} \omega_{n}\right)},
$$$$
k_{m}(t)=1+\sum_{i=1}^{N} \frac{k_{A i}}{k_{m}} \cos \left(i \omega_{h} t+\varphi_{k}\right) \text {, }
$$$$
\varsigma_{m}=\frac{c_{m}}{\left(2 m_{e} \omega_{n}\right)}
$$$$
f\left(x_{n}\right)=\bar{f}\left(\bar{x}_{n}\right)= \begin{cases}f\left(x_{n}\right)-1, & f\left(x_{n}\right)>1, \\ 0, & -1 \leq f\left(x_{n}\right) \leq 1, \\ f\left(x_{n}\right)+1, & f\left(x_{n}\right)<-1,\end{cases}
$$$$
(i=1,2, \ldots, 8 ; j=x, y, z) \text {. }
$$

Substituting (10) into (9), the 14-DOF differential equations are transformed to the no-dimensional form, and the further simplification is possible. Combining (1), (2), and (10), the parameter $x_{3}$ can be altered as

$$
\begin{aligned}
& x_{3}=\frac{R_{3} \theta_{3}}{b}=\frac{R_{3}}{b} \arctan \frac{\tan b x_{2} / R_{2}}{\cos \alpha}, \\
& \dot{x}_{3}=\frac{R_{3} \dot{\theta}_{3}}{b \omega_{n}}=\frac{R_{3}}{b \omega_{n}} \frac{1}{M_{2}} \dot{\theta}_{2}=\frac{R_{3} \dot{x}_{2}}{R_{1} M_{2}}, \\
& \ddot{x}_{3}=\frac{R_{3} \ddot{\theta}_{3}}{b \omega_{n}^{2}}=\frac{R_{3}}{R_{1} M_{2}} \ddot{x}_{2}-\frac{2 B \sin 2 \theta_{2}}{M_{2}^{2}} \frac{R_{3} b}{R_{1}^{2}}\left(\dot{x}_{2}\right)^{2}, \\
& T_{3}=\frac{T_{2} \dot{\theta}_{2}}{\dot{\theta}_{3}}=T_{2} M_{2} .
\end{aligned}
$$

Similarly, the parameter $x_{4}$ shares the aforementioned relationship, so $x_{3}$ and $x_{4}$ can be expressed by $x_{2}$ and $x_{5}$ separately:

$$
\begin{aligned}
M_{i} & =A-B \cos 2 \theta_{i}, \\
P_{i} & =2 B \sin 2 \theta_{i},
\end{aligned}
$$

$$
(i=2,5) \text {. }
$$

The relationship between the driven gear and differential is given by

$$
\begin{aligned}
& \theta_{6}=\theta_{7}, \\
& T_{6}=2 T_{7} .
\end{aligned}
$$


Combining (10)-(13), (9) can be simplified to the following 11-DOF differential equations:

$$
\begin{aligned}
& \ddot{x}_{1}+2 \varsigma_{1}\left(\dot{x}_{1}-\dot{x}_{2}\right)+k_{1}\left(x_{1}-x_{2}\right)-\frac{T_{1}}{b \omega_{n}^{2} m_{1} R_{1}}=0, \\
& \left(m_{2} R_{1}+\frac{m_{3} R_{3}^{2}}{R_{1} M_{2}^{2}}\right) \ddot{x}_{2}-\frac{m_{3} P_{2}}{M_{2}^{3}} \frac{R_{3}^{2} b}{R_{1}^{2}}\left(\dot{x}_{2}\right)^{2}+2\left(m_{2} R_{1} \varsigma_{2}\right. \\
& \left.+\frac{m_{3} \varsigma_{3} R_{3}^{2}}{R_{1} M_{2}^{2}}\right) \dot{x}_{2}-2 m_{2} R_{1} \varsigma_{2} \dot{x}_{1}-\frac{2 m_{3} \varsigma_{3} R_{4} R_{3}}{R_{5} M_{5} M_{2}} \dot{x}_{5} \\
& +k_{2} m_{2} R_{1} x_{2}-k_{2} m_{2} R_{1} x_{1} \\
& +\frac{k_{3} m_{3} R_{3}}{b M_{2}}\left[R_{3} \arctan \frac{\tan \left(b x_{2} / R_{2}\right)}{\cos \alpha}\right. \\
& \left.-R_{4} \arctan \frac{\tan \left(b x_{5} / R_{5}\right)}{\cos \alpha}\right]=0, \\
& \left(m_{5} R_{5}+\frac{m_{4} R_{4}^{2}}{R_{5} M_{5}^{2}}\right) \ddot{x}_{5}+\frac{2 m_{4} \varsigma_{4} R_{4}}{M_{5}}\left(\frac{R_{4}}{R_{5} M_{5}} \dot{x}_{5}\right. \\
& \left.-\frac{R_{3}}{R_{1} M_{2}} \dot{x}_{2}\right)+a_{3} k_{5}(t) m_{5} R_{5} f\left(x_{n}\right) \\
& +\frac{k_{4} m_{4} R_{4}}{b M_{5}}\left[R_{4} \arctan \frac{\tan \left(b x_{5} / R_{5}\right)}{\cos \alpha}\right. \\
& \left.-R_{3} \arctan \frac{\tan \left(b x_{2} / R_{2}\right)}{\cos \alpha}\right]-\frac{m_{4} P_{5}}{M_{5}^{3}} \frac{R_{4}^{2} b}{R_{5}^{2}}\left(\dot{x}_{5}\right)^{2} \\
& +2 a_{3} m_{5} \varsigma_{5} \dot{x}_{n}=0 \\
& \left(\frac{m_{6} R_{6}^{2}+2 m_{7} R_{7}^{2}}{R_{6}}\right) \dot{x}_{6}+2 m_{7} R_{7}\left[\varsigma_{7}\left(\frac{R_{7}}{R_{6}} \dot{x}_{6}-\dot{x}_{8}\right)\right.
\end{aligned}
$$

$$
\begin{aligned}
& \left.+k_{7}\left(\frac{R_{7}}{R_{6}} x_{6}-x_{8}\right)\right]-a_{3} m_{6} R_{6}\left[k_{6} f\left(x_{n}\right)-2 \xi_{6} \dot{x}_{n}\right] \\
& =0 \text {, } \\
& m_{8} \ddot{x}_{8}+2 m_{8} \varsigma_{8}\left(\dot{x}_{8}-\frac{R_{7}}{R_{6}} \dot{x}_{6}\right)+m_{8} k_{8}\left(x_{8}-\frac{R_{7}}{R_{6}} x_{6}\right) \\
& +\frac{T_{8}}{b \omega_{n}^{2} R_{8}}=0 \\
& \ddot{x}_{p}+2 \varsigma_{p x} \dot{x}_{p}+k_{p x} x_{p}+2 a_{1} \varsigma_{m p x} \dot{x}_{n}+a_{1} k_{m p x}(t) f\left(x_{n}\right) \\
& =0 \text {, } \\
& \ddot{y}_{p}+2 \varsigma_{p y} \dot{y}_{p}+k_{p y} y_{p}+2 a_{2} \varsigma_{m p y} \dot{x}_{n}+a_{2} k_{m p y}(t) f\left(x_{n}\right) \\
& =0 \text {, } \\
& \ddot{z}_{p}+2 \varsigma_{p z} \dot{z}_{p}+k_{p z} z_{p}+2 a_{3} \varsigma_{m p z} \dot{x}_{n}+a_{3} k_{m p z}(t) f\left(x_{n}\right) \\
& =0 \text {, } \\
& \ddot{x}_{g}+2 \varsigma_{g x} \dot{x}_{g}+k_{g x} x_{g}-2 a_{1} \varsigma_{m g x} \dot{x}_{n}-a_{1} k_{m g x}(t) f\left(x_{n}\right) \\
& =0 \text {, } \\
& \ddot{y}_{g}+2 \varsigma_{g y} \dot{y}_{g}+k_{g y} y_{g}-2 a_{2} \varsigma_{m g y} \dot{x}_{n}-a_{2} k_{m g y}(t) f\left(x_{n}\right) \\
& =0 \text {, } \\
& \ddot{z}_{g}+2 \varsigma_{g z} \dot{z}_{g}+k_{g z} z_{g}-2 a_{3} \varsigma_{m g z} \dot{x}_{n}-a_{3} k_{m g z}(t) f\left(x_{n}\right) \\
& =0 \text {. }
\end{aligned}
$$

\section{Numerical Analysis}

To solve the vibration response of the system, the state space variables $\{q\}$ are introduced:

$$
\{q\}=\left\{\begin{array}{llllllllllllllllllllll}
q_{1} & q_{2} & q_{3} & q_{4} & q_{5} & q_{6} & q_{7} & q_{8} & q_{9} & q_{10} & q_{11} & q_{12} & q_{13} & q_{14} & q_{15} & q_{16} & q_{17} & q_{18} & q_{19} & q_{20} & q_{21} & q_{22}
\end{array}\right\}^{T} .
$$

Select the state space variables:

$$
\begin{aligned}
& q_{1}=x_{1}, \\
& q_{2}=\dot{x}_{1}, \\
& q_{3}=x_{2}, \\
& q_{4}=\dot{x}_{2}, \\
& q_{5}=x_{5}, \\
& q_{6}=\dot{x}_{5}, \\
& q_{7}=x_{6}, \\
& q_{8}=\dot{x}_{6}, \\
& q_{9}=x_{8},
\end{aligned}
$$

$$
\begin{aligned}
& q_{10}=\dot{x}_{8}, \\
& q_{11}=x_{p}, \\
& q_{12}=\dot{x}_{p}, \\
& q_{13}=y_{p}, \\
& q_{14}=\dot{y}_{p}, \\
& q_{15}=z_{p}, \\
& q_{16}=\dot{z}_{p}, \\
& q_{17}=x_{g}, \\
& q_{18}=\dot{x}_{g},
\end{aligned}
$$




$$
\begin{aligned}
& q_{19}=y_{g}, \\
& q_{20}=\dot{y}_{g}, \\
& q_{21}=z_{g}, \\
& q_{22}=\dot{z}_{g} .
\end{aligned}
$$

Combining (15) and (16), (14) can be altered as

$$
\begin{aligned}
& \dot{q}_{1}=q_{2}, \\
& \dot{q}_{2}=\frac{T_{1}}{b \omega_{n}^{2} m_{1} R_{1}}-2 \varsigma_{1}\left(q_{2}-q_{4}\right)-k_{1}\left(q_{1}-q_{3}\right), \\
& \dot{q}_{3}=q_{4} \text {, } \\
& \dot{q}_{4}=\left[\frac{m_{3} P_{2}}{M_{2}^{3}} \frac{R_{3}^{2} b}{R_{1}^{2}} q_{4}^{2}-2\left(m_{2} R_{1} \varsigma_{2}+m_{3} \varsigma_{3} \frac{R_{3}^{2}}{R_{1} M_{2}^{2}}\right) q_{4}\right. \\
& +2 m_{2} R_{1} \varsigma_{2} q_{2}+\frac{2 m_{3} \varsigma_{3} R_{4} R_{3}}{R_{5} M_{5} M_{2}} q_{6}-k_{2} m_{2} R_{1} q_{3} \\
& +k_{2} m_{2} R_{1} q_{1}-\frac{k_{3} m_{3} R_{3}^{2}}{b M_{2}} \arctan \frac{\tan \left(b q_{3} / R_{2}\right)}{\cos \alpha} \\
& \left.+\frac{k_{3} m_{3} R_{4} R_{3}}{b M_{2}} \arctan \frac{\tan \left(b q_{5} / R_{5}\right)}{\cos \alpha}\right]\left(m_{2} R_{1}\right. \\
& \left.+\frac{m_{3} R_{3}^{2}}{R_{1} M_{2}^{2}}\right)^{-1} \\
& \dot{q}_{5}=q_{6}, \\
& \dot{q}_{6}=\left[\frac{m_{4} P_{5}}{M_{5}^{3}} \frac{R_{4}^{2} b}{R_{5}^{2}} q_{6}^{2}-\frac{2 m_{4} \varsigma_{4} R_{4}}{M_{5}}\left(\frac{R_{4}}{R_{5} M_{5}} q_{6}\right.\right. \\
& \left.-\frac{R_{3}}{R_{1} M_{2}} q_{4}\right)-a_{3} k_{5}(t) m_{5} R_{5} f\left(x_{n}\right) \\
& -2 a_{3} m_{5} \varsigma_{5}\left[\left(q_{12}-q_{18}\right) a_{1}+\left(q_{14}-q_{20}\right) a_{2}\right. \\
& \left.+\left(q_{16}-q_{22}+q_{6}-q_{8}\right) a_{3}-\dot{e}(t)\right] \\
& -\frac{k_{4} m_{4} R_{4}}{b M_{5}}\left(R_{4} \arctan \frac{\tan \left(b q_{5} / R_{5}\right)}{\cos \alpha}\right. \\
& \left.\left.-R_{3} \arctan \frac{\tan \left(b q_{3} / R_{2}\right)}{\cos \alpha}\right)\right]\left(m_{5} R_{5}+\frac{m_{4} R_{4}^{2}}{R_{5} M_{5}^{2}}\right)^{-1} ; \\
& \dot{q}_{7}=q_{8} \\
& \dot{q}_{8}=\left[-2 m_{7} \varsigma_{7} R_{7}\left(\frac{R_{7}}{R_{6}} q_{8}-q_{10}\right)-2 m_{7} k_{7} R_{7}\left(\frac{R_{7}}{R_{6}} q_{7}\right.\right. \\
& \left.-q_{9}\right)+a_{3} k_{6} m_{6} R_{6} f\left(x_{n}\right)
\end{aligned}
$$

$$
\begin{aligned}
& +2 a_{3} m_{6} \xi_{6} R_{6}\left[\left(q_{12}-q_{18}\right) a_{1}+\left(q_{14}-q_{20}\right) a_{2}\right. \\
& \left.\left.+\left(q_{16}-q_{22}+q_{6}-q_{8}\right) a_{3}-\dot{e}(t)\right]\right]\left(m_{6} R_{6}\right. \\
& \left.+\frac{2 m_{7} R_{7}^{2}}{R_{6}}\right)^{-1},
\end{aligned}
$$

$$
\dot{q}_{9}=q_{10}
$$$$
\dot{q}_{10}=\frac{T_{8}}{b \omega_{n}^{2} m_{8} R_{8}}-2 \varsigma_{8}\left(q_{10}-\frac{R_{7}}{R_{6}} q_{8}\right)-k_{8}\left(q_{9}-\frac{R_{7}}{R_{6}}\right.
$$$$
\left.\cdot q_{7}\right)
$$$$
\dot{q}_{11}=q_{12},
$$$$
\dot{q}_{12}=-2 \varsigma_{p x} q_{12}-k_{p x} q_{11}-a_{1} k_{m p x}(t) f\left(x_{n}\right)
$$$$
-2 a_{1} \varsigma_{m p x}\left[\left(q_{12}-q_{18}\right) a_{1}+\left(q_{14}-q_{20}\right) a_{2}+\left(q_{16}\right.\right.
$$$$
\left.\left.-q_{22}+q_{6}-q_{8}\right) a_{3}-\dot{e}(t)\right]
$$

$$
\dot{q}_{13}=q_{14} \text {, }
$$$$
\dot{q}_{14}=-2 \varsigma_{p y} q_{14}-k_{p y} q_{13}-a_{2} k_{m p y}(t) f\left(x_{n}\right)
$$$$
-2 a_{2} \varsigma_{m p y}\left[\left(q_{12}-q_{18}\right) a_{1}+\left(q_{14}-q_{20}\right) a_{2}+\left(q_{16}\right.\right.
$$$$
\left.\left.-q_{22}+q_{6}-q_{8}\right) a_{3}-\dot{e}(t)\right]
$$

$\dot{q}_{15}=q_{16}$,

$$
\begin{aligned}
\dot{q}_{16} & =-2 \varsigma_{p z} q_{16}-k_{p z} q_{15}-a_{3} k_{m p z}(t) f\left(x_{n}\right) \\
& -2 a_{3} \varsigma_{m p z}\left[\left(q_{12}-q_{18}\right) a_{1}+\left(q_{14}-q_{20}\right) a_{2}+\left(q_{16}\right.\right. \\
& \left.\left.-q_{22}+q_{6}-q_{8}\right) a_{3}-\dot{e}(t)\right]
\end{aligned}
$$

$\dot{q}_{17}=q_{18}$,

$$
\begin{aligned}
\dot{q}_{18} & =-2 \varsigma_{g x} q_{18}-k_{g x} q_{17}+a_{1} k_{m g x}(t) f\left(x_{n}\right) \\
& +2 a_{1} \varsigma_{m g x}\left[\left(q_{12}-q_{18}\right) a_{1}+\left(q_{14}-q_{20}\right) a_{2}+\left(q_{16}\right.\right. \\
& \left.\left.-q_{22}+q_{6}-q_{8}\right) a_{3}-\dot{e}(t)\right]
\end{aligned}
$$$$
\dot{q}_{19}=q_{20} \text {, }
$$$$
\dot{q}_{20}=-2 \varsigma_{g y} q_{20}-k_{g y} q_{19}+a_{2} k_{m g y}(t) f\left(x_{n}\right)
$$$$
+2 a_{2} s_{m g y}\left[\left(q_{12}-q_{18}\right) a_{1}+\left(q_{14}-q_{20}\right) a_{2}+\left(q_{16}\right.\right.
$$$$
\left.\left.-q_{22}+q_{6}-q_{8}\right) a_{3}-\dot{e}(t)\right]
$$$$
\dot{q}_{21}=q_{22} \text {, }
$$$$
\dot{q}_{22}=-2 \varsigma_{g z} q_{22}-k_{g z} q_{21}+a_{3} k_{m g z}(t) f\left(x_{n}\right)
$$$$
+2 a_{3} \varsigma_{m g z}\left[\left(q_{12}-q_{18}\right) a_{1}+\left(q_{14}-q_{20}\right) a_{2}+\left(q_{16}\right.\right.
$$$$
\left.\left.-q_{22}+q_{6}-q_{8}\right) a_{3}-\dot{e}(t)\right] \text {. }
$$ 
TABLE 1: Parameters of the drive shaft.

\begin{tabular}{|c|c|c|c|c|}
\hline Parameters & $\begin{array}{c}\text { Shear } \\
\text { modulus } \\
G(\mathrm{GPa})\end{array}$ & $\begin{array}{c}\text { Length of } \\
\text { the shaft } \\
L(\mathrm{~mm})\end{array}$ & $\begin{array}{l}\text { Outside } \\
\text { diameter } \\
D(\mathrm{~mm})\end{array}$ & $\begin{array}{c}\text { Inside } \\
\text { diameter } \\
d(\mathrm{~mm})\end{array}$ \\
\hline Shaft 1 & 79.4 & 508 & 63.5 & 59.9 \\
\hline Shaft 2 & 79.4 & 879 & 63.5 & 59.9 \\
\hline $\begin{array}{l}\text { Left (right) } \\
\text { half-shaft }\end{array}$ & 82.8 & 719.5 & $\begin{array}{l}31 \text { (solid } \\
\text { circular } \\
\text { section) }\end{array}$ & \\
\hline
\end{tabular}

TABle 2: Parameters of the pinion and gear.

\begin{tabular}{lccc}
\hline & Pinion & & Gear \\
\hline $\begin{array}{l}\text { Number of teeth } \\
\text { Transverse module }\end{array}$ & 8 & 4.161 & 41 \\
$\begin{array}{l}\text { Average pressure } \\
\text { angle (ALPHA) }\end{array}$ & & $21.25^{\circ}$ & \\
$\begin{array}{l}\text { Pitch diameter }\left(D_{0}\right) \\
(\mathrm{mm})\end{array}$ & 170.6 & \\
$\begin{array}{l}\text { Offset distance }(\mathrm{mm}) \\
\text { Mean spiral angle } \\
\text { (BETA) }\end{array}$ & $47.97^{\circ}$ & 25 (lower) & \\
$\begin{array}{l}\text { Pitch cone angle } \\
\text { (DELTA-B) }\end{array}$ & $12.75^{\circ}$ & & $28.27^{\circ}$ \\
$\begin{array}{l}\text { Tooth width }(\mathrm{BF}) \\
(\mathrm{mm})\end{array}$ & 33.02 & & $76.50^{\circ}$ \\
$\begin{array}{l}\text { Base circle diameter } \\
\left(D_{b}\right)\end{array}$ & & $D_{b}=D_{0} * \cos (\mathrm{ALPHA})$ & \\
\hline
\end{tabular}

TABLE 3: Values of the torsional stiffness and damping.

\begin{tabular}{lccc}
\hline $\begin{array}{l}\text { Torsional stiffness } \\
(\mathrm{N} \cdot \mathrm{mm} / \mathrm{rad})\end{array}$ & Value & $\begin{array}{c}\text { Torsional damping } \\
(\mathrm{N} \cdot \mathrm{mm} \cdot \mathrm{s} / \mathrm{rad})\end{array}$ & Value \\
\hline$K_{1}, K_{2}$ & 51945.046 & $c_{1}, c_{2}$ & 1310.286 \\
$K_{3}, K_{4}$ & 30020.572 & $c_{3}, c_{4}$ & 1310.286 \\
$K_{7}, K_{8}$ & 652.11800 & $c_{7}, c_{8}$ & 437.416 \\
\hline
\end{tabular}

The vibration characteristics of the system can be obtained by solving (17) with Runge-Kutta method.

4.1. Parameter Setting. The main parameters of the drive shaft and gear pair are listed in Tables 1 and 2.

Based on the initial parameters, the torsional stiffness and damping of the shaft-final drive system are calculated in Table 3. The average torsional stiffness and damping of the gear pair are as follows:

$$
\begin{aligned}
& k_{m}=k_{m b}\left(\frac{r_{b 1}^{2}+r_{b 2}^{2}}{2 r_{b 1}^{2} r_{b 2}^{2}}\right), \\
& c_{m}=2 \xi_{m} \sqrt{k_{m b}\left(\frac{1}{m_{p}}+\frac{1}{m_{g}}\right)},
\end{aligned}
$$

where $r_{b 1}, r_{b 2}$ are the pitch circle radius of the pinion and gear, $m_{p}, m_{g}$ are the masses of the pinion and gear, $k_{m b}$ is the gear mesh stiffness with a linear value: $1.84 \times 10^{3} \mathrm{~N} / \mathrm{mm}$, and $\xi_{m}$ is
TABLE 4: Values of the equivalent moment of inertia and equivalent mass.

\begin{tabular}{lccc}
\hline $\begin{array}{l}\text { Equivalent } \\
\text { moment of } \\
\text { inertia } \\
\left(\mathrm{kg} \cdot \mathrm{mm}^{2}\right)\end{array}$ & Value & Equivalent mass $(\mathrm{kg})$ & Value \\
\hline$J_{1}$ & 952.242 & $m_{p x}$ & 1.012 \\
$J_{2}$ & 2106.616 & $m_{p y}$ & 1.012 \\
$J_{3}, \ldots, J_{4}$ & 1979.326 & $m_{p z}$ & 1.012 \\
$J_{5}$ & 955.202 & $m_{g x}$ & 5.115 \\
$J_{6}$ & 17122.301 & $m_{g y}$ & 5.115 \\
$J_{7}$ & 10329.170 & $m_{g z}$ & 5.115 \\
$J_{8}$ & 124675.6 & & \\
\hline
\end{tabular}

the damping ratio with a value of 0.1 here. Then the equivalent polar moment of inertia of the first transmission shaft at Node 1 of the $U$-joint can be described as

$$
J_{1}=\frac{1}{2}\left(J_{s z z 1}+J_{z 1}\right)+J_{c d c 1} .
$$

$J_{s z z 1}$ is the first universal joint cross-shaft's equivalent polar moment of inertia about the first transmission axis, $J_{z 1}$ is the first transmission shaft's equivalent polar moment of inertia about its geometric centre, and $J_{c d c 1}$ is the first joint shaft fork's equivalent polar moment of inertia about the first transmission axis. Similarly, the equivalent moment of inertia and equivalent mass can be calculated by the 3D CAD model, and the values are listed in Table 4.

In the gear system, there are two parallel TRBs for supporting the pinion and the other two TRBs for supporting the gear. The equivalent method is an effective way to deal with the bearing stiffness; the equivalent stiffness and damping of the bearings along $x$-, $y$-, and $z$-axes are obtained as

$$
\begin{aligned}
K_{p j} & =\frac{K_{p j 1}}{2}+\frac{K_{p j 2}}{2}, \\
c_{p j} & =\frac{c_{p j 1}}{2}+\frac{c_{p j 2}}{2}, \\
K_{g j} & =\frac{K_{g j 1}}{2}+\frac{K_{g j 2}}{2}, \\
c_{g j} & =\frac{c_{g j 1}}{2}+\frac{c_{g j 2}}{2},
\end{aligned}
$$

where $K_{i j 1}, K_{i j 2}, c_{i j 1}, c_{i j 2}(i=p, g ; j=x, y, z)$ are the four different bearing stiffnesses and dampings.

4.2. Results at the Given Speed. Considering the drive shaft at a speed of $2000 \mathrm{rpm}$, and the input torque $T_{1}=2.2 \times$ $10^{5} \mathrm{~N} \cdot \mathrm{mm}$, the influence of bearing stiffness on the coupled flexural-torsional vibration of the shaft-final drive system can be analyzed. A bearing stiffness coefficient $a$ is introduced in this paper. Figure 3 shows the output dynamic response of the shaft and driven gear. The speed fluctuation value first increases and then decreases, but the fluctuation value of 


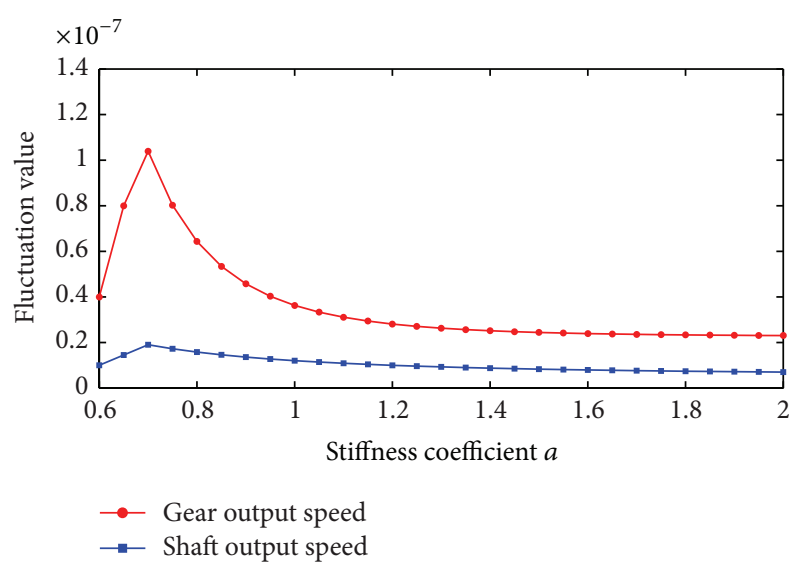

FIGURE 3: Influence of bearing stiffness on torsional vibration of the system.

driven gear is more sensitive to the different bearing stiffness coefficients. When the coefficient $a$ is 0.7 , the fluctuation maximum occurs; it is because different bearing stiffness can change the system natural frequency, and the system resonance region appears at a certain excitation frequency corresponding to $a=0.7$. In cases where other parameters remain constant, the shaft and gear speed fluctuations are significantly reduced as the bearing stiffness coefficient $a>$ 0.7 ; when it increases to a critical value, the reduction trend becomes less obvious.

Figures 4(a) and 4(b) show the bending vibration of the hypoid gear when the coefficient increases from 0.6 to 2.0. By comparison under the same conditions, a maximum displacement response occurs along $z$-axis, and the minimal fluctuation occurs along $y$-axis, the displacement response along $x$-axis and $z$-axis has little difference, and the response of pinion is stronger than gear. Considering the influence of different bearing stiffness on bending vibration system, the displacement response follows a similar trend to the torsional vibration in Figure 3, and the displacement fluctuation increases to a peak value and then moves downward to the steady state.

4.3. Results at the Different Speeds. For further analysis of the vibration characteristics, the gear transmission errors under different speeds are considered. Figure 5 shows the vibration response when the stiffness coefficient varies from 0.7 to 1.5 and the drive shaft input speed changes from $800 \mathrm{rpm}$ to $5000 \mathrm{rpm}$, in which a speed variation coefficient $n_{v}$ is used to describe the drive excitation.

Figure 5(a) shows the displacement fluctuation of the transmission error under different stiffness coefficients and different input regions, partial enlargements are shown in Figures 5(b) and 5(c), and the parameters in the resonance region of the system vary with the stiffness, but the resonance regions mainly occur from 1.45 to 1.65 and 2.00 to 2.20 . In the regions of $1.45 \leq n_{v} \leq 1.65$, the maximum fluctuation occurs when $a$ is 1.3 , and the dimensionless value is $4.84 \times$ $10^{-5}$, but the fluctuation region is not obvious compared with other speed regions (see Figure 5(b)). In the regions of $2.00 \leq n_{v} \leq 2.20$, the minimum fluctuation occurs when $a=1.2$ and then follows by 0.8 and 1.0, but when $a$ is 1.5 , the fluctuation increases significantly (see Figure 5(c)). Overall, the transmission error has a nonlinear relationship with the stiffness coefficient, considering the different input speeds; when $a$ is $0.8,1.0$, and 1.2 , the fluctuations are relatively smaller; meanwhile the influence on transmission error fluctuation is not obvious with the other stiffness coefficients.

The bearing stiffness exerts a significant influence on the vibration characteristics of the shaft-final drive system. When the bearing stiffness increases at $2000 \mathrm{rpm}$, the speed fluctuation first increases and then decreases; when it increases to a critical value, the reduction trend is hardly changeable; then the resonance regions of the coupled system vary with the bearing stiffness under different speeds. Obviously, the system has a comprehensive minimum fluctuation at $a=1.2$.

\section{Dynamic Simulation}

To investigate the dynamic response of the system under different bearing stiffness, a rigid-flexible coupling model is established in the ADAMS software, and then by introducing variables DV_1, DV_2, DV_3, and DV_4, where DV_1 and DV 2 are the damping and bearing stiffness of the pinion and DV_3 and DV_4 are the damping and bearing stiffness of the gear, the model adopts a Bushing connection to simulate the bearing, and the rotational stiffness and damping values are set to 0 ; then the measure functions of the virtual prototype model are established. The simulation is based on the following: the input speed is $2000 \mathrm{rpm}$, the load torque is $2.2 \times 10^{5} \mathrm{~N} \cdot \mathrm{mm}$, and the speed fluctuation coefficient which comes from the engine experiments of the vehicle is 0.025 .

As the bearing stiffness increases, the fluctuations in a certainty scope on output speed and torque of the system are nonlinear and complicated, and the output of drive shaft and driven gear could well describe the system performance, especially the influence of different bearing stiffness on coupling vibration of the shaft-final drive assembly. For the quantitative analysis, Trial 1 Trial 14 represent fourteen sets of data successively in Figure 6, corresponding to $0.6 \leq a \leq 1.9$; it means that Trial 1 represents $a=0.6$, and Trial 14 represents $a=1.9$. Figures $6(\mathrm{a})$ and $6(\mathrm{~b})$ show the output speed and torque fluctuations of drive shaft. From Trial 5 to Trial 7 (1.0 $\leq a \leq 1.2$ ), the output speed fluctuations change slowly and the values are relatively small, but the output torque is not identical: the fluctuations are obvious in regions of $0.6 \leq a \leq$ 0.8 and $1.6 \leq a \leq 1.9$, the minimum value occurs at $a=1.5$, and it is relatively smooth and steady at $1.2 \leq a \leq 1.4$.

Similarly, Figure 7 shows the fluctuation curves of driven gear output speed and torque. Fourteen sets of data, Trial 1 Trial 14, are also selected as the variables corresponding to 0.6 $\leq a \leq 1.9$. From Trial 5 to Trial 7 , the output speed and torque fluctuations are obvious in the regions of $0.6 \leq a \leq 0.8$ or 1.6 $\leq a \leq 1$.9. Figures $7(\mathrm{a})$ and $7(\mathrm{~b})$ show the similar fluctuation trend under different bearing stiffness and change slowly at $1.2 \leq a \leq 1.5$.

The simulation results in Figures 6 and 7 show that the dynamics of shaft-final drive system is affected by the bearing 


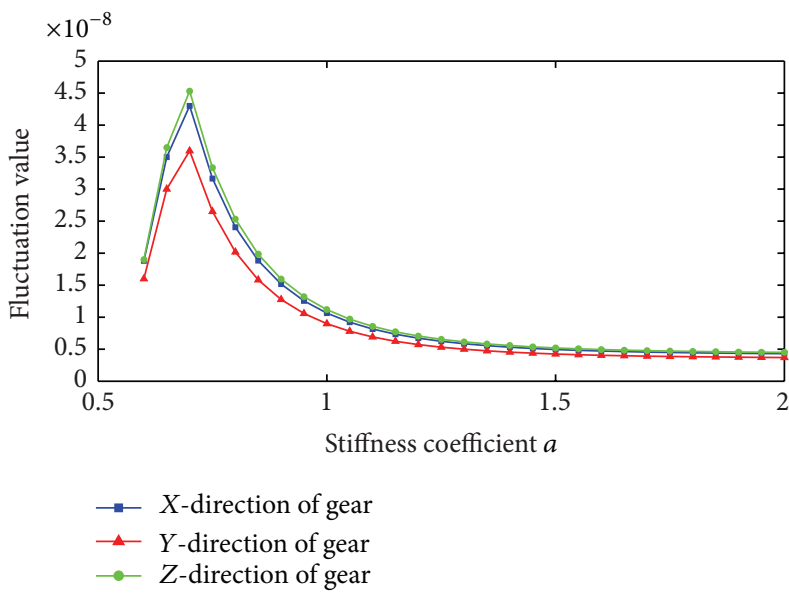

(a)

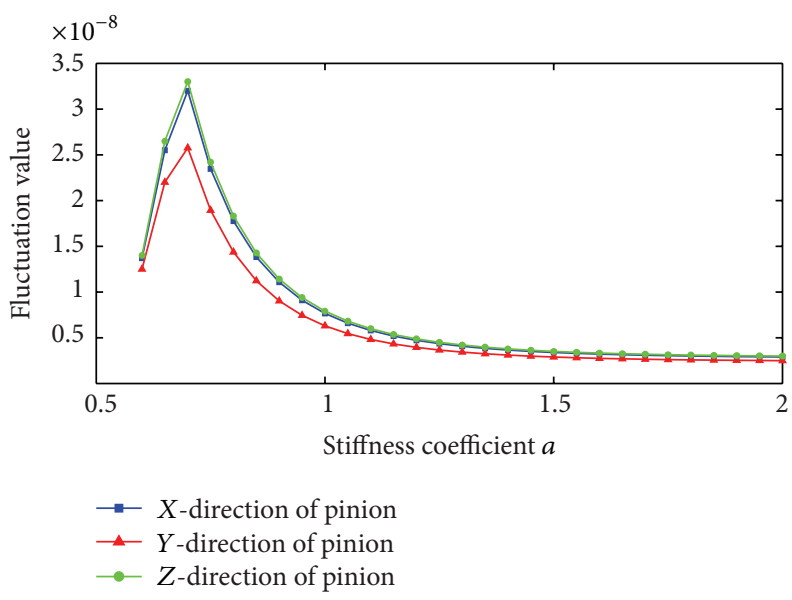

(b)

FIGURE 4: Influence of bearing stiffness on bending vibration of the hypoid gear.
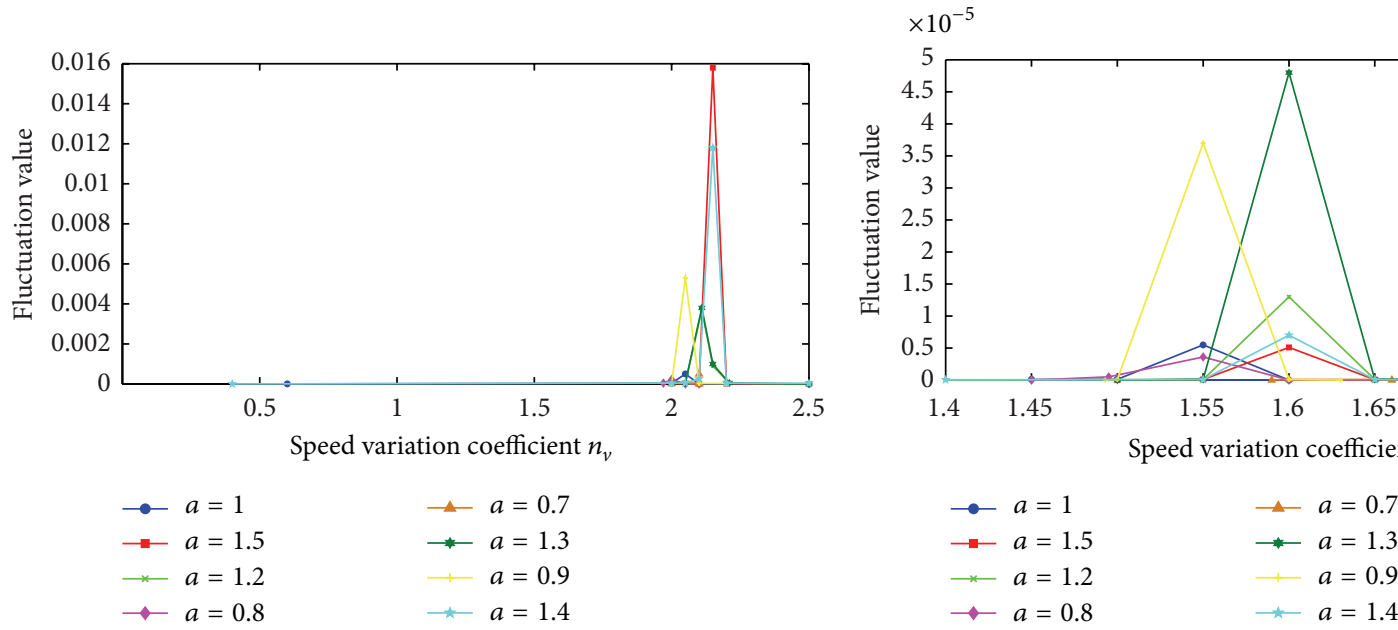

(a)

(b)

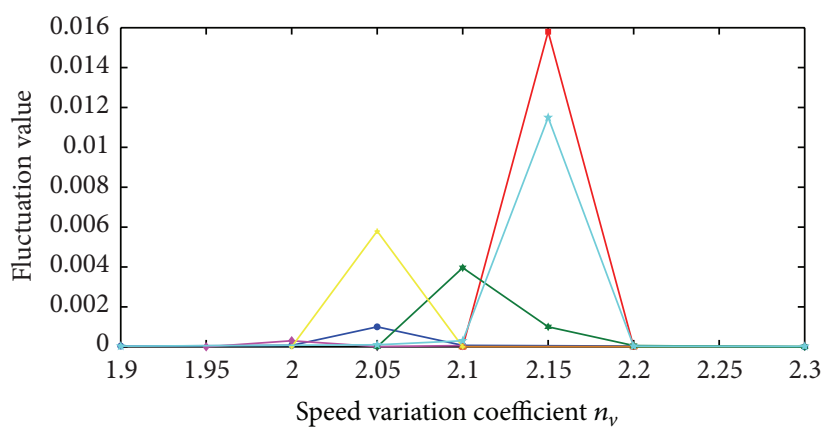

$$
\begin{aligned}
& \longrightarrow-a=1 \\
& \text { - } a=1.2 \\
& \triangle a=0.7 \\
& - \\
& \text { - }-a=1.3 \\
& +a=0.9 \\
& \rightarrow a=1.4
\end{aligned}
$$

(c)

FIGURE 5: Gear transmission error $x_{n}$. 


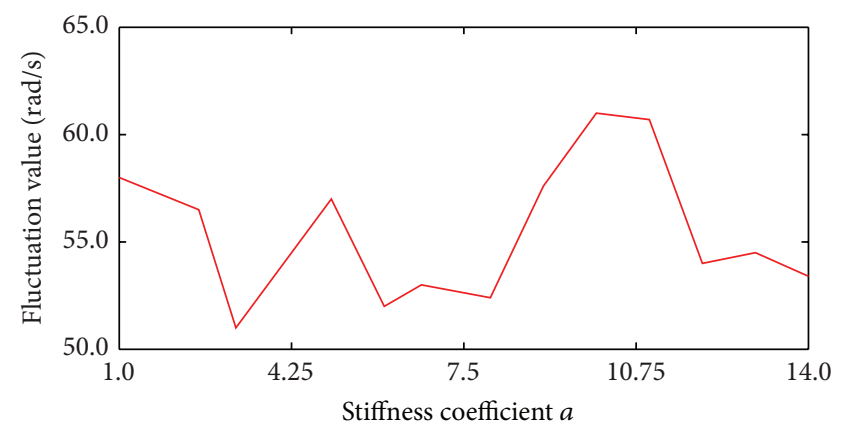

— Drive shaft output speed

(a)

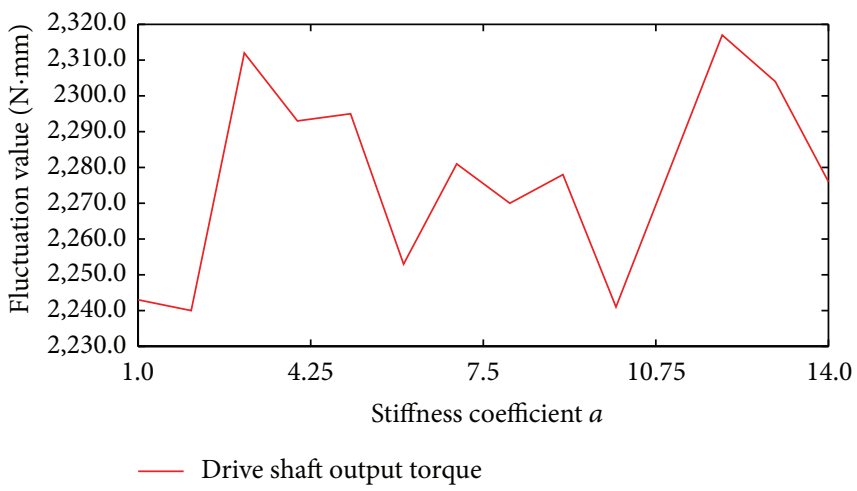

(b)

FIGURE 6: Output speed and torque of the drive shaft.

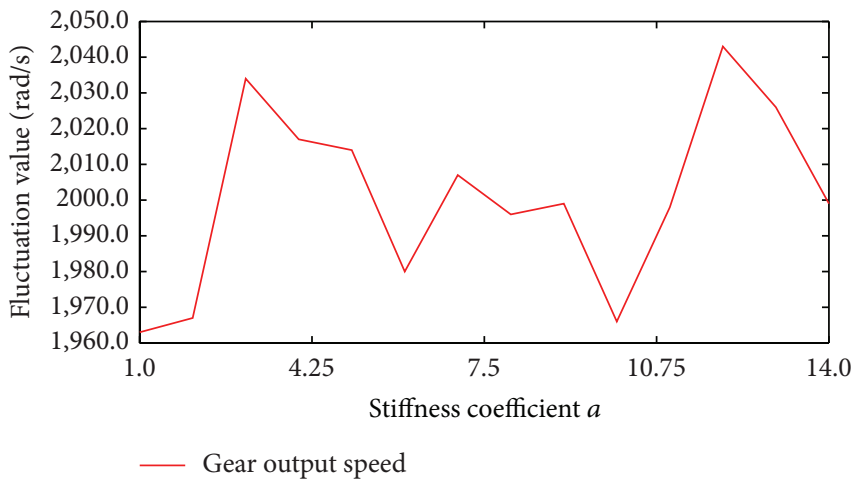

(a)

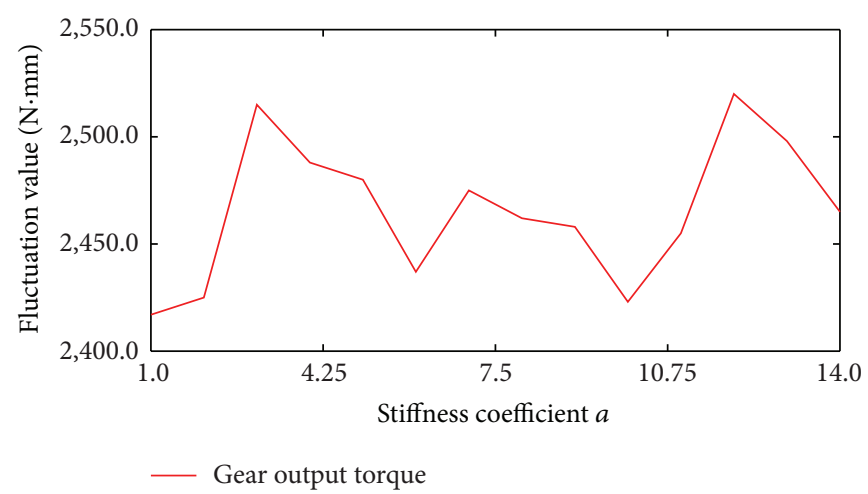

(b)

FIGURE 7: Output speed and torque fluctuations of the driven gear.

stiffness. Considering the output fluctuations of drive shaft and driven gear, and the influence of gear transmission error, the fluctuation values of drive shaft are lower than that of driven gear. Compared with the initial speed and torque, the fluctuations are relatively smaller. From the fluctuation trend, there exists a reasonable region of bearing stiffness coefficient $1.2 \leq a \leq 1.5$ in which the dynamic fluctuations of the shaftfinal drive system keep a smaller and steady state.

In fact, the speed and torque fluctuations are closely related to engine output dynamics and transmission ratio. When running in the 3rd gear, the power matching parameters in detail are as shown in Table 5.

The curves of seven different colours from $a 1$ to $a 7$ which represent the output fluctuations under different speeds are shown in Figure 8, corresponding to seven groups of bearing stiffness. The selected stiffness reflects the key dynamics of this shaft-final drive system as it originates from the base points: $0.6,0.7,0.8,1.0,1.2,1.3$, and 1.5 in turn. Figures $8(a)$ and 8 (b) are the output speed fluctuation curves of drive shaft and driven gear.

In Figure 8(a), the output fluctuations of drive shaft increase as the input speed increases at $1.0 \leq a \leq 1.5$, but the fluctuations increase sharply above $3570 \mathrm{rpm}$ from 0.6 to 0.8 . Figure 8(b) shows that the output fluctuations are not obvious under different bearing stiffness at the low input speeds, and
TABLE 5: Drive shaft input speed/torque matching parameters.

\begin{tabular}{lccccccc}
\hline $\begin{array}{l}\text { Engine output } \\
\text { speed } \\
\text { (rpm) }\end{array}$ & 2500 & 3000 & 3500 & 4000 & 4500 & 5000 & 5500 \\
\hline $\begin{array}{l}\text { Engine output } \\
\text { torque } \\
\times 10^{3}(\mathrm{~N} \cdot \mathrm{mm})\end{array}$ & 99 & 104 & 108 & 110 & 109 & 106 & 104 \\
\hline $\begin{array}{l}\text { Output speed in } \\
\text { third gear } \\
(\mathrm{rpm})\end{array}$ & 1785.7 & 2142.9 & 2500 & 2857.1 & 3214.3 & 3571.4 & 3928.6 \\
\hline $\begin{array}{l}\text { Output torque } \\
\text { in third gear } \\
\times 10^{3}(\mathrm{~N} \cdot \mathrm{mm})\end{array}$ & 138.6 & 145.6 & 151.2 & 154 & 152.6 & 148.4 & 145.6 \\
\hline
\end{tabular}

it is minimal from 1800 to $2400 \mathrm{rpm}$ at $a=0.8$. However, the curves show an obvious difference above $3500 \mathrm{rpm}$, the difference is minimal at $a=1.2$ and then follows by 1.3 and 1.5 , and the fluctuations of driven gear have a sudden change at $0.6 \leq a \leq 0.8$.

\section{Experimental Verification}

From the above theoretical analysis, the influence of bearing stiffness on the nonlinear dynamics of a shaft-final drive 


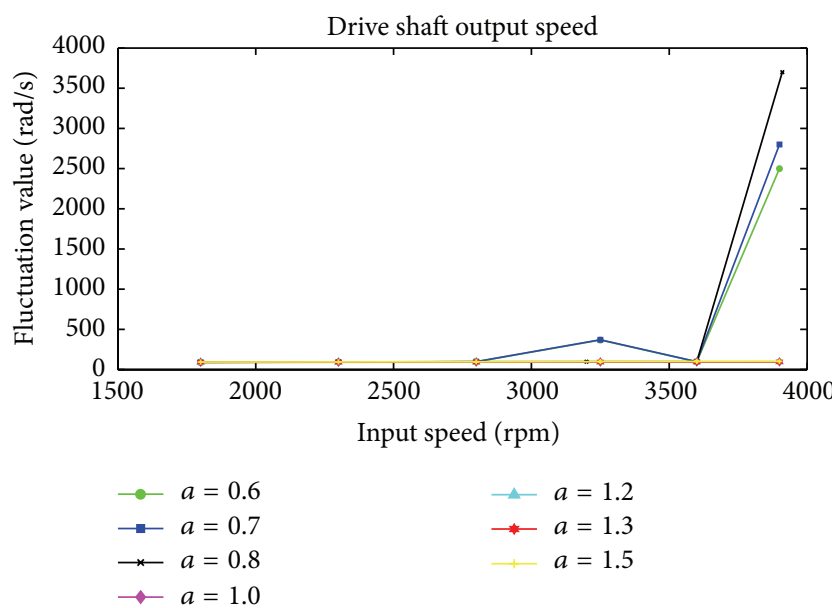

(a)

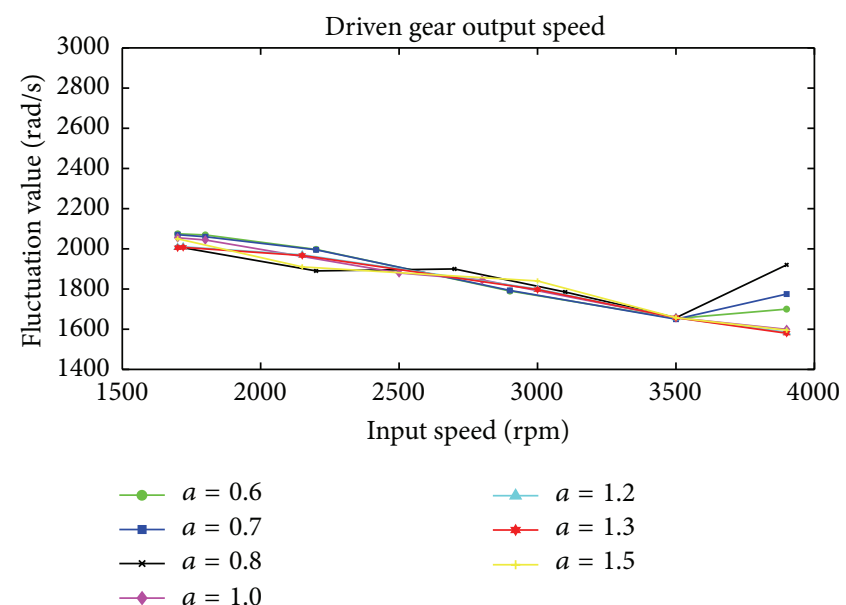

(b)

FIgURE 8: Speed fluctuations of the drive shaft and driven gear.

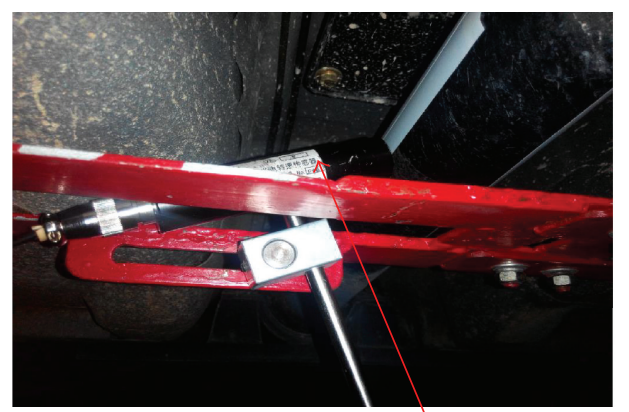

Photoelectric sensor

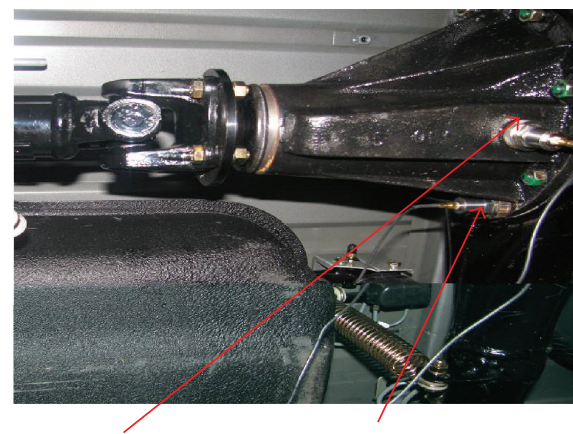

The vertical direction The axial direction

Figure 9: Layout and installation of two sensors.

system is obvious, and the different bearing stiffness coefficients lead to the resonance parameters of the system changing. In the installation process, bearing preload adjustment is a simple and effective method to change the bearing stiffness, but it is still not enough for the improved system. To obtain suitable preload adjustment, the initial bearing pairs are replaced by other ones with the improved stiffness. Comparison test of the initial $(a=1.0)$ and optimized bearing stiffness $(a=1.2)$ of the drive system is designed to analyze the rear axle vibration behaviour and interior noise under different conditions.

6.1. Shaft-Final Drive System Vibration Behaviour. For obtaining better test results, the self-developed software of Portable vibration noise performance testing system is designed by Wuhan University of Technology (WUT) to detect the relationship between shaft speed and rear axle vibration in vehicle driving. Its hardware part consists of computer, sensors, DAQ Card, preamplifier, and so forth and the key structure components are shown in Figure 9.

There are two different types of sensors: one is photoelectric sensor, which is used to detect the speed; its magnetic base is fixed on flat chassis, and it is installed to vertical alignment of reflective tape pasted in the drive shaft keeping
$20 \mathrm{~mm}$ distance; the other is the vibration acceleration sensor, which is used to rear axle vibration behaviour. The two sensors are fixed on the reducer along vertical and horizontal axis, the signal lines connect two channels of instrument box, and the sensitivity values are $4.77 \mathrm{pc} / \mathrm{s}^{2}$ and $4.94 \mathrm{pc} / \mathrm{s}^{2}$, respectively.

In order to analyze the relative error between the simulation and experiment, comparative analysis is used to research the system response. The speed fluctuations of driven gear which reflect the system output characteristics are obvious compared to that of drive shaft; it can be tested in the shaftfinal drive assembly with the Rear axle noise test platform in SAIC-GM-Wuling Automobile Co., Ltd. (SGMW). The statistical data are listed in Table 6.

From the comparative analysis in Table 6, the results of dynamic simulation match with the experiment data in the commonly used speed range of $1500 \mathrm{rpm}-3000 \mathrm{rpm}$, the relative errors of the initial and optimized driven gear speed fluctuations are less than $3 \%$, the relative error maximum is $2.36 \%$ at $a=1.0$ with the input speed of $1500 \mathrm{rpm}$, and the fluctuations at $a=1.2$ are less than that at $a=1.0$; it can be interpreted as the excitation frequency is away from the system natural frequency at $a=1.2$, which can provide good vibration characteristics. Overall, the relative errors of the 


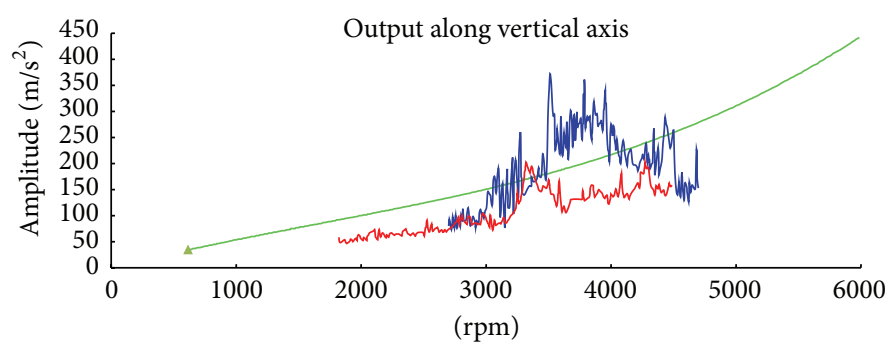

Target-5th gear-WOT and Coast down
$-\quad$ th gear-WOT
$-\quad$ th gear-Coast down

(a1) Initial test

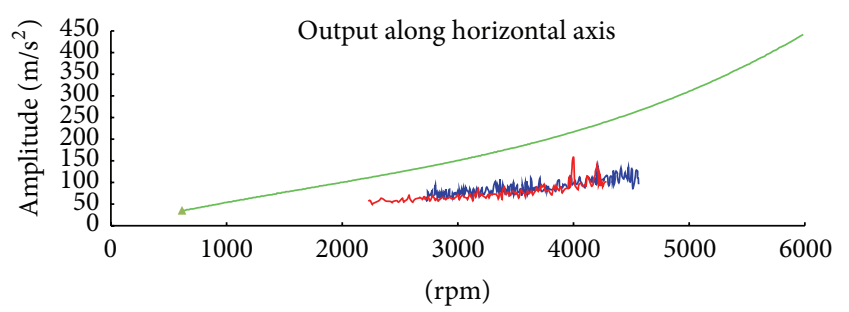

Target-5th gear-WOT and Coast down
5th gear-WOT
5th gear-Coast down

(b1) Initial test

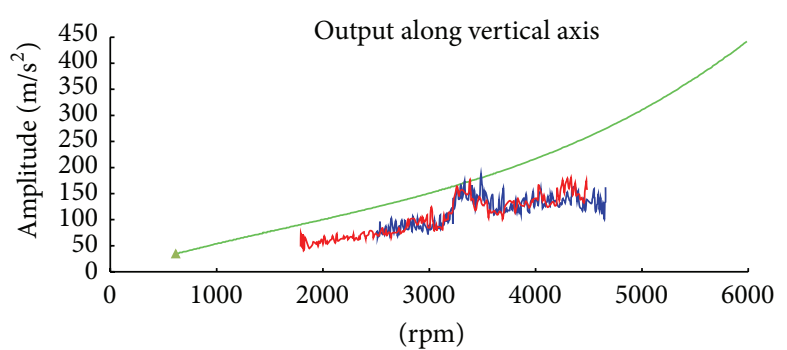

_ Target-5th gear-WOT and Coast down

— 5 th gear-WOT

- 5th gear-Coast down

(a2) Improved test

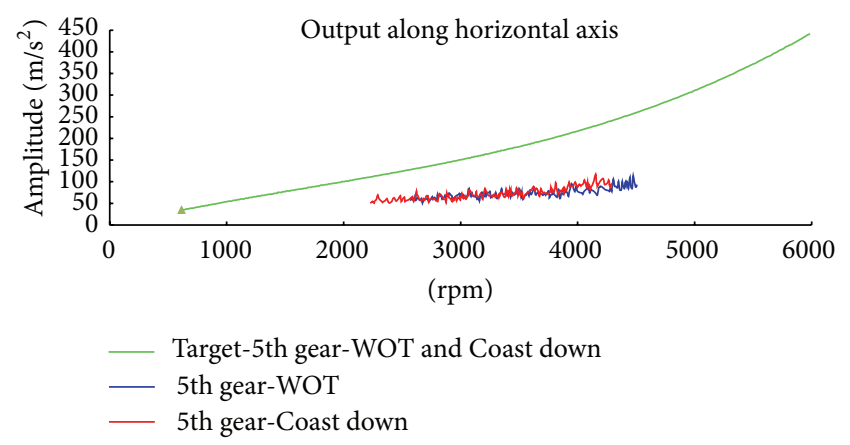

(b2) Improved test

FIgURE 10: Test curves along vertical and horizontal axis.

TABLE 6: Comparative analysis on the speed fluctuations of the driven gear.

\begin{tabular}{ccccc}
\hline \multirow{6}{*}{$a=1.0$} & $\begin{array}{c}\text { Input speed } \\
(\mathrm{rpm})\end{array}$ & $\begin{array}{c}\text { Simulation } \\
(\mathrm{rad} / \mathrm{s})\end{array}$ & $\begin{array}{c}\text { Experiment } \\
\text { data } \\
(\mathrm{rad} / \mathrm{s})\end{array}$ & $\begin{array}{c}\text { Relative error } \\
(\%)\end{array}$ \\
\hline \multirow{6}{*}{$a=1.2$} & 1500 & 2053.29 & 2101.80 & 2.36 \\
& 2000 & 2014.77 & 2028.05 & 0.66 \\
& 2500 & 1953.95 & 1975.70 & 1.11 \\
& 3000 & 1899.10 & 1931.92 & 1.72 \\
\hline \multirow{6}{*}{$* 300$} & 2034.05 & 2074.88 & 2.01 \\
& 2500 & 2005.67 & 2015.74 & 0.50 \\
& 3000 & 1947.22 & 1966.38 & 0.98 \\
\hline
\end{tabular}

simulation and experiment results follow the same trend; the dynamic simulation can meet the system test accuracy.

When the field test layout is finished, the vibration responses under different conditions are obtained in the test, and the initial and improved vibration signals along vertical and horizontal axis are shown in Figure 10.

In Figure 10, the vertical fluctuations are larger from $3200 \mathrm{rpm}$ to $3500 \mathrm{rpm}$ and stronger than those along horizontal axis obviously. The dynamic behaviour is slightly different under different conditions, considerable fluctuation mainly occurs from $3500 \mathrm{rpm}$ to $4200 \mathrm{rpm}$ in Figure 10(a1), and it has an abrupt horizontal vibration in 5th gear of WOT in
Figure 10(b1). Compared with the initial test, the improved vibration signals shown in Figures 10(a2) and 10(b2) are more stable, and the vertical fluctuation amplitudes are below the target; this trend is obvious from $3500 \mathrm{rpm}$ to $4200 \mathrm{rpm}$.

6.2. Interior Noise in Vehicle Driving. LMS Test. Lab is widely adopted for data acquisition and processing in vehicle $\mathrm{NVH}$ performance evaluation. In the test road, the repetitive tests of the Wide Open Throttle (WOT) and Coast down with 5th gear are finished with the test system, and then the initial and improved vertical vibration signals are shown in Figure 11.

In Figure 11(a), the interior noise mostly ranges from $42.5 \mathrm{~dB}$ to $67.5 \mathrm{~dB}$ in WOT and $40 \mathrm{~dB}$ to $57.5 \mathrm{~dB}$ in Coast down; the peak occurs at $2900 \mathrm{rpm}$ and $3500 \mathrm{rpm}$ nearby; when the bearing stiffness is improved in Figure 11(b), the overall interior noise decreases obviously by comparison, especially in the peak region from $2900 \mathrm{rpm}$ to $3500 \mathrm{rpm}$. When running at a low speed, the average decibel value is larger than the initial test, but the noise level is mostly below the target, which reflects the consistency to the theoretical analysis on the nonlinear dynamics of the shaft-final drive system.

\section{Conclusions}

A 14-DOF coupled vibration model of a shaft-final drive system is established; the influence of nonlinear factors was considered. Based on the deduced dynamic differential equations, numerical analysis method is adopted to analyze the 

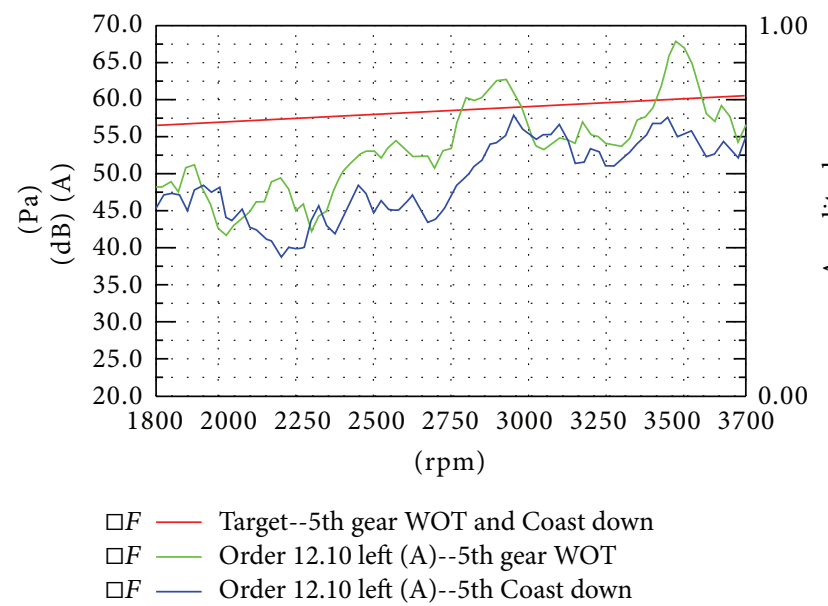

(a) Initial test

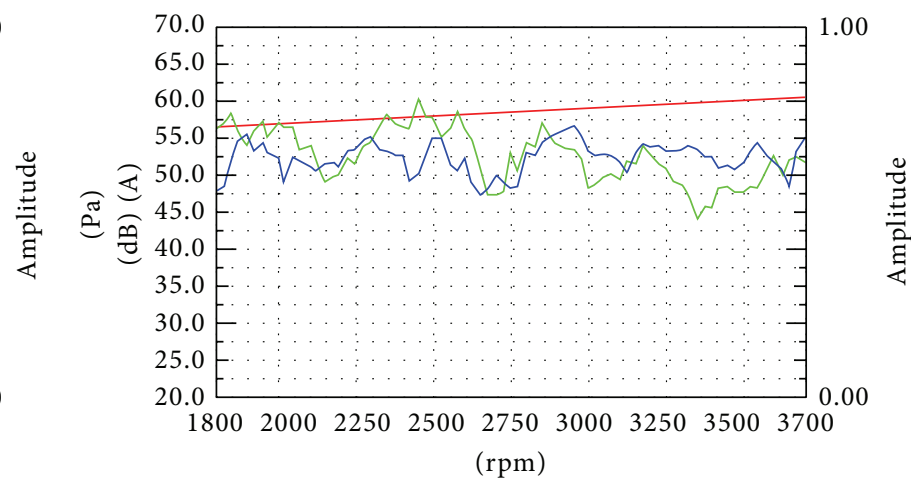

$\square F-$ Target--5th gear WOT and Coast down
$\square F-$ Order 12.10 left (A)--5th gear WOT
$\square F-$ Order 12.10 left (A)--5th Coast down

(b) Improved test

FIGURE 11: Interior noise test under different conditions.

dynamic response with the introduced stiffness coefficient. Results show that improving the bearing stiffness can reduce the vibration response at the given speed; when the bearing stiffness increases to a critical value, the reduction becomes insignificant, and the resonance regions of the coupled system vary with the bearing stiffness at the different driving speeds.

Influence of different bearing stiffness on the nonlinear system was simulated to investigate the dynamic response at the given speed and different speeds. When the stiffness coefficient $a$ is 1.2, compared with other coefficients, the output fluctuations of the drive shaft and gear can be decreased, and the system performance improves significantly. Then the experiments on the system vibration behaviour and interior noise in vehicle driving were carried out, and the selfdeveloped software of Portable vibration noise performance testing system was designed for performance detection of the vibration system. By comparative analysis of the initial and improved system, the vibration behaviour and interior noise can be improved when $a$ is 1.2; meanwhile, the relative error analysis of the simulation and experiment demonstrates the correction of numerical results.

\section{Nomenclature}

$\theta_{i}: \quad$ Angular displacement of transmission components (where $i=1, \ldots, 10$ )

$x_{i}, y_{i}, z_{i}$ : Displacement of hypoid gear pair along $x-$, $y$-, and $z$-axes (where $i=p, g$ )

$c_{m}: \quad$ Average damping of hypoid gear

$\alpha_{n}: \quad$ Normal pressure angle

$\beta_{1}$ : $\quad$ Mean spiral angle

$\delta_{1}$ : $\quad$ Pitch cone angle

$x_{n}$ : $\quad$ Relative displacement of normal direction at the contact point

a: $\quad$ Bearing stiffness coefficient (ratio of selected stiffness and initial bearing stiffness)

$n_{v}: \quad$ Speed variation coefficient (ratio of selected speed and given speed) $k_{m}$ : Mean mesh stiffness

$k_{A i}$ : Fluctuation amplitude in $i$ th order

$\Omega_{h}$ : Mesh frequency of hypoid gear

$\varphi_{k}$ : Initial phase of dynamic mesh stiffness

$R_{i}$ : Radius of pinion and gear at the contact point (where $i=p, g$ )

$b$ : Half of gear backlash

$\varphi_{e}:$ Initial phase of static transmission error

$e_{0}$ : Mean transmission error at the contact point

$e_{A i}$ : Transmission error in $i$ th order at the contact point

$J_{i}$ : Equivalent moment of inertia of transmission components (where $i=1, \ldots, 8)$

$m_{j i}$ : Equivalent lumped mass of pinion and gear (where $i=p, g ; j=x, y, z$; $\left.m_{x p}=m_{y p}=m_{z p}, \quad m_{x g}=m_{y g}=m_{z g}\right)$

$K_{i}$ : Equivalent stiffness of shaft (where $i=1, \ldots, 4$ ) and half-shaft (where $i=7,8$ )

$c_{i}$ : Damping of shaft (where $i=1, \ldots, 4$ ) and half-shaft (where $i=7,8$ )

$K_{i j}$ : Equivalent stiffness along $x$-, $y$-, and $z$-axes (where $i=p, g ; j=x, y, z$ )

$c_{i j}$ : Equivalent damping along $x-, y-$, and $z$-axes (where $i=p, g ; j=x, y, z$ ).

\section{Competing Interests}

The authors declare that there is no conflict of interests regarding the publication of this paper.

\section{Acknowledgments}

This work was supported and funded by the Cooperation and Exchange Projects of Guangxi Science and Technology Department (Grant no. 1346011-6) and the Scientific and Technological Project (Grant no. 2013F020202). Thanks are due to SAIC-GM-Wuling Automobile Co., Ltd., for assistance 
with the experiments and the technical proposal throughout the work.

\section{References}

[1] M. Gnanakumarr, S. Theodossiades, H. Rahnejat, and M. Menday, "Impact-induced vibration in vehicular driveline systems: theoretical and experimental investigations," Proceedings of the Institution of Mechanical Engineers, Part K: Journal of MultiBody Dynamics, vol. 219, no. 1, pp. 1-12, 2005.

[2] T. Wellmann, K. Govindswamy, E. Braun, and K. Wolff, "Aspects of driveline integration for optimized vehicle $\mathrm{NVH}$ characteristics," SAE 2007-01-2246, SAE International, 2007.

[3] T. C. Lim and R. Singh, "Vibration transmission through rolling element bearings, part I: bearing stiffness formulation," Journal of Sound and Vibration, vol. 139, no. 2, pp. 179-199, 1990.

[4] M. G. Donley, T. C. Lim, and G. C. Steyer, "Dynamic analysis of automotive gearing systems," Journal of Passenger Cars, vol. 101, no. 905, pp. 77-87, 1992.

[5] G. D. Bibel, A. Kumar, S. Reddy, and R. Handschuh, "Contact stress analysis of spiral bevel gears using finite element analysis," Journal of Mechanical Design, vol. 117, no. 2, pp. 235-240, 1995.

[6] C. Gosselin, L. Cloutier, and Q. D. Nguyen, "A general formulation for the calculation of the load sharing and transmission error under load of spiral bevel and hypoid gears," Mechanism and Machine Theory, vol. 30, no. 3, pp. 433-450, 1995.

[7] S. Theodossiades and S. Natsiavas, "Non-linear dynamics of gear-pair systems with periodic stiffness and backlash," Journal of Sound and Vibration, vol. 229, no. 2, pp. 287-310, 2000.

[8] J. Wang, T. C. Lim, and M. Li, "Dynamics of a hypoid gear pair considering the effects of time-varying mesh parameters and backlash nonlinearity," Journal of Sound and Vibration, vol. 308, no. 1-2, pp. 302-329, 2007.

[9] S. Wang, Y. Shen, and H. Dong, "Nonlinear dynamical characteristics of a spiral bevel gear system with backlash and timevarying stiffness," Chinese Journal of Mechanical Engineering, vol. 39, no. 2, pp. 28-32, 2003.

[10] M. Li and H. Y. Hu, "Dynamic analysis of a spiral bevel-geared rotor-bearing system," Journal of Sound and Vibration, vol. 259, no. 3, pp. 605-624, 2003.

[11] Y. Cheng and T. C. Lim, "Dynamic analysis of high speed hypoid gears with emphasis on the automotive axle noise problem," in Proceeding of the ASME Power Transmission and Gearing Conference, DETC98/PTG-5784, Atlanta, Ga, USA, 1998.

[12] Y. Cheng, Dynamics of high-speed hypoid and bevel geared rotor systems [Ph.D. thesis], Ohio State University, 2000.

[13] P. Tao, Coupled multi-body dynamic and vibration analysis of hypoid and bevel geared rotor system [Ph.D. thesis], University of Cincinnati, 2010.

[14] J. Yang and T. Lim, "Dynamics of coupled nonlinear hypoid gear mesh and time-varying bearing stiffness systems," $S A E$ International Journal of Passenger Cars-Mechanical Systems, vol. 4, no. 2, pp. 1039-1049, 2011.

[15] C. H. Kang, W. C. Hsu, E. K. Lee, and T. N. Shiau, "Dynamic analysis of gear-rotor system with viscoelastic supports under residual shaft bow effect," Mechanism and Machine Theory, vol. 46, no. 3, pp. 264-275, 2011.

[16] T. N. Shiau, C. H. Kang, D. S. Liu, E. K. Lee, and W. C. Hsu, "Optimization design of the geared rotor system with critical speed constraints using the enhanced genetic algorithm," in Proceedings of the ASME Turbo Expo 2008: Power for Land, Sea, and Air, International Gas Turbine Institute, Berlin, Germany, June 2008.

[17] A. S. Lee, J. W. Ha, and D.-H. Choi, "Coupled lateral and torsional vibration characteristics of a speed increasing geared rotor-bearing system," Journal of Sound and Vibration, vol. 263, no. 4, pp. 725-742, 2003.

[18] J. Han and L. Shi, "Study on kinematic mechanism of misalignment fault of rotor system connected by gear coupling," Journal of Vibration Engineering, vol. 17, no. 4, pp. 416-420, 2004.

[19] S. P. Harsha, "Non-linear dynamic response of a balanced rotor supported on rolling element bearings," Mechanical Systems and Signal Processing, vol. 19, no. 3, pp. 551-578, 2005.

[20] J.-J. Sinou, "Non-linear dynamics and contacts of an unbalanced flexible rotor supported on ball bearings," Mechanism and Machine Theory, vol. 44, no. 9, pp. 1713-1732, 2009.

[21] C. Villa, J.-J. Sinou, and F. Thouverez, "Stability and vibration analysis of a complex flexible rotor bearing system," Communications in Nonlinear Science and Numerical Simulation, vol. 13, no. 4, pp. 804-821, 2008.

[22] X. Jinli, S. Xingyi, and P. Bo, "Numerical analysis and demonstration: transmission shaft influence on meshing vibration in driving and driven gears," Shock and Vibration, vol. 2015, Article ID 365084, 10 pages, 2015.

[23] A. A. Shabana, A. K. Aboubakr, and L. Ding, "Use of the noninertial coordinates in the analysis of train longitudinal forces," Journal of Computational and Nonlinear Dynamics, vol. 7, no. 1, Article ID 011001, 10 pages, 2012. 


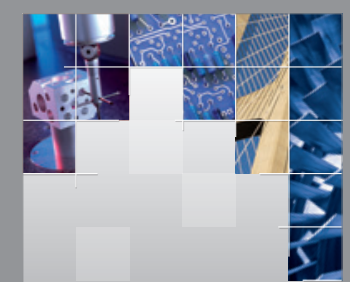

\section{Enfincering}
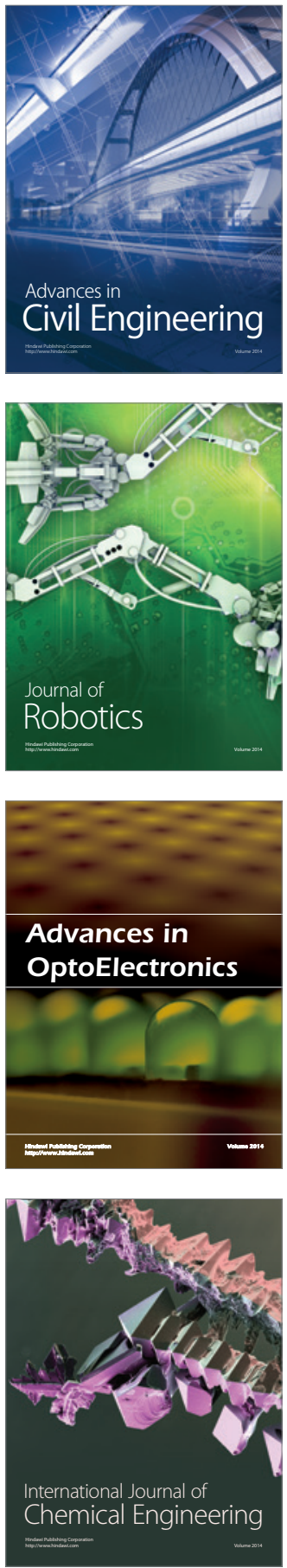

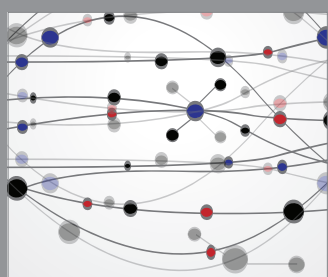

The Scientific World Journal

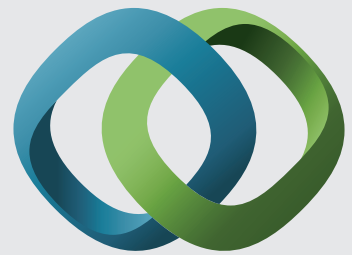

\section{Hindawi}

Submit your manuscripts at

http://www.hindawi.com
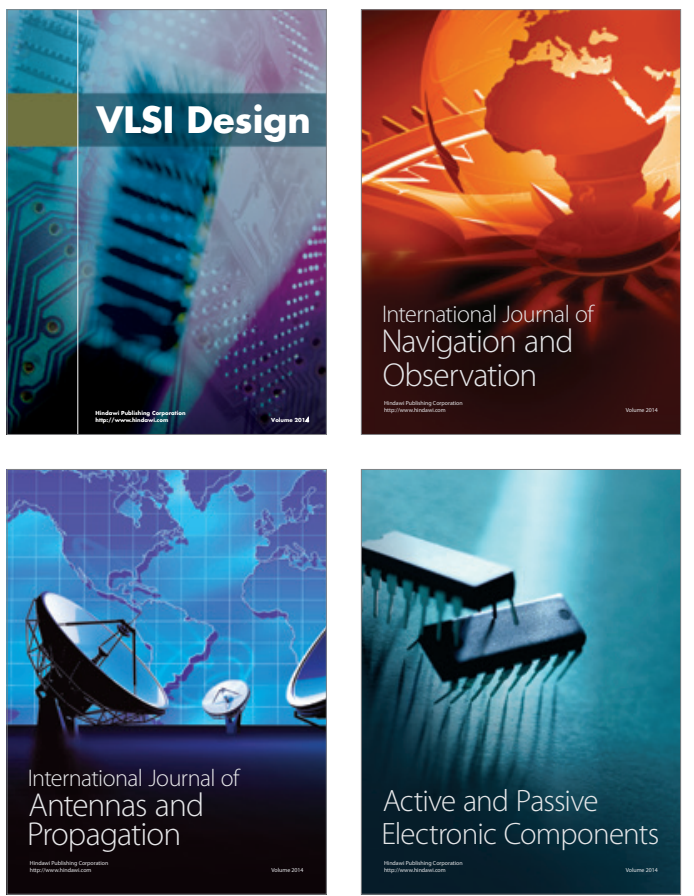
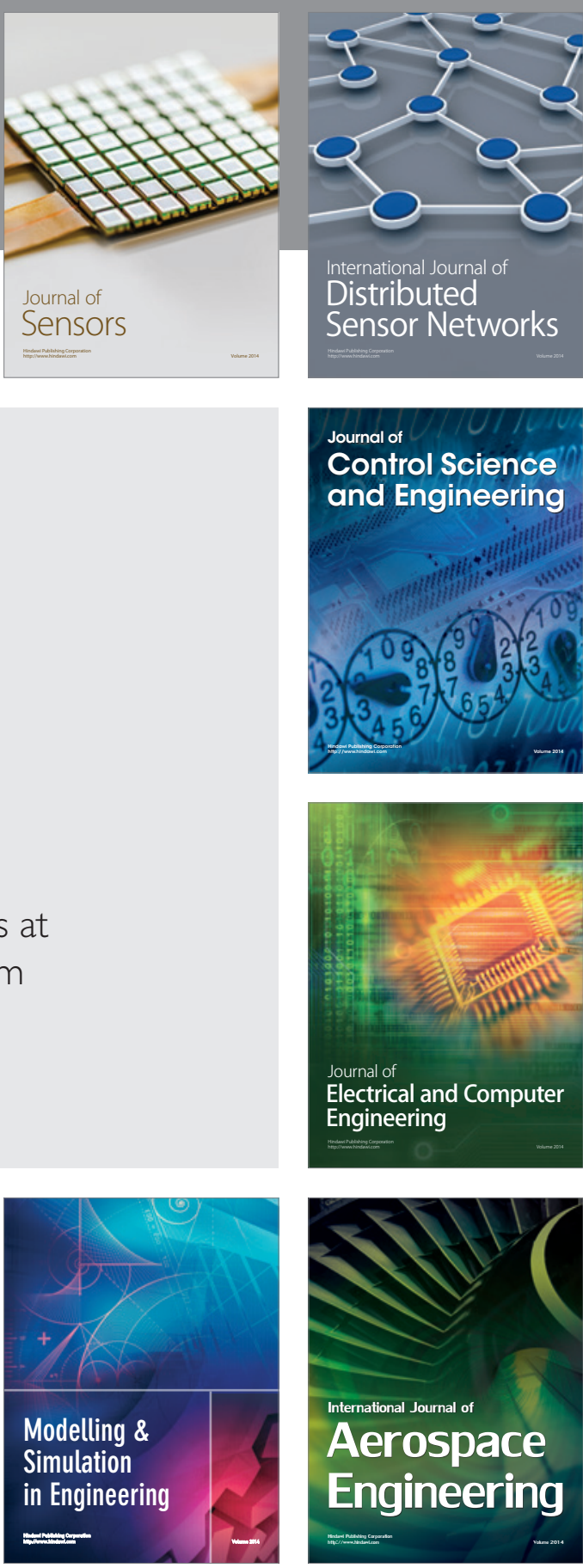

International Journal of

Distributed

Sensor Networks

Journal of

Control Science

and Engineering
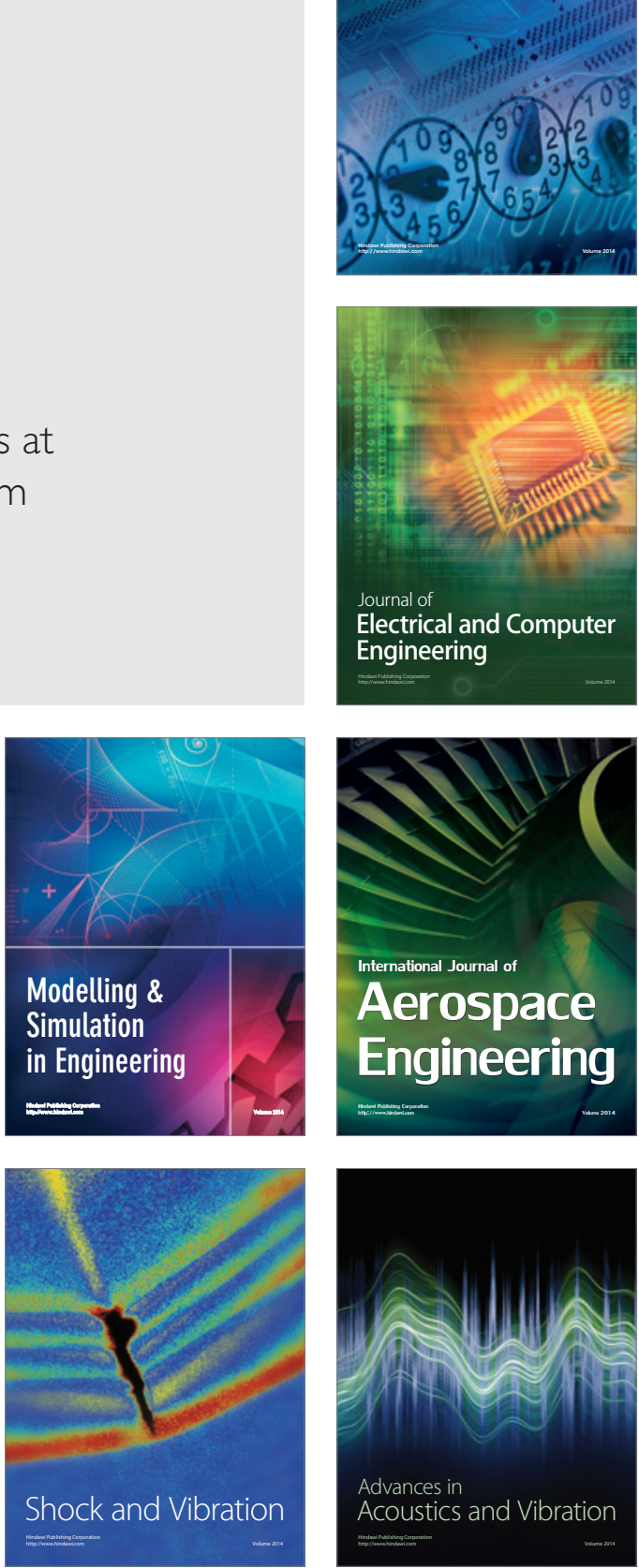